\title{
UMA BREVE REVISÃO SOBRE A CATÁLISE POR ÁTOMOS ISOLADOS: CONCEITOS E APLICAÇÕES
}

\author{
Luanne E. M. Ferreira ${ }^{a}$, Ruan S. A. Ribeiro ${ }^{a}$, Vinicius G. C. Madriaga ${ }^{a}$, Sancler C. Vasconcelos ${ }^{a}$, Eric T. T. Shimabukuro ${ }^{a}$, \\ Vinicius Rossa ${ }^{a}$, Sara S. Vieira ${ }^{\mathrm{a}}$, Fabio B. Passos ${ }^{\mathrm{b}, \#}$ e Thiago M. Lima ${ }^{\mathrm{a}, *, \mathbb{1}}$ \\ a'Departamento de Química Inorgânica, Instituto de Química, Universidade Federal Fluminense, 24020-141, Niterói - RJ, Brasil \\ bDepartamento de Engenharia Química e de Petróleo, Universidade Federal Fluminense, 24210-240, Niterói - RJ, Brasil
}

Recebido em 04/07/2021; aceito em 14/08/2021; publicado na web em 15/09/2021

\begin{abstract}
A BRIEF OVERVIEW ON SINGLE-ATOM CATALYSIS: CONCEPTS AND APPLICATIONS. Catalytic processes became extremely important for the development of our society, especially after the second industrial revolution. Thus, the research for more efficient catalysts is an obstacle to overcome to achieve cheaper processes, higher yields, and selectivity of desired products. In this context, single-atom catalysis emerges as a promising alternative to unite the advantages of traditional homogeneous and heterogeneous catalysis. Catalysis by single-atoms is a bridge that unites in a single catalyst the ease of recovery and reuse (from heterogeneous catalysis) with the high exposure and uniformity of sites (from homogeneous catalysis). Thus, single-atom catalysts (SACs) and single-atom alloys (SAAs) have already found several applications in the literature, such as in hydrogenation, oxidation, conversion of biomass derivatives, electrocatalysis, and photocatalysis. However, it is essential to emphasize that it is still a field that is expanding and relatively new, with several opportunities and many barriers to surpass. In this review, concepts of homogeneous, enzymatic, and heterogeneous catalysis will be addressed, as well as fundamental aspects of single-atom catalysis, preparation methods, characterization, and current challenges.
\end{abstract}

Keywords: catalysis; single-atom catalysis; single-atom alloys; SACs; SAAs.

\section{INTRODUÇÃO}

As reações químicas estão presentes nas bases da nossa sociedade e de nosso desenvolvimento. Nesse sentido, diversos obstáculos do nosso progresso como sociedade foram superados graças aos avanços de tecnologias químicas que nos forneceram importantes produtos como fármacos, vacinas, fertilizantes, combustíveis e aditivos alimentícios. De certa forma, podemos associar nosso desenvolvimento e avanço científico-tecnológico atual com a inserção de processos químicos mais eficientes nas indústrias química e farmacêutica, sendo especialmente atrelado ao uso de catalisadores. A inserção dos catalisadores nestes processos possibilitou a obtenção de produtos em larga escala e com especificidades (quimio e estereoseletividades), que por meio reações térmicas não seriam possíveis. ${ }^{1-6}$

De acordo com a definição da IUPAC, os catalisadores são substâncias que têm a capacidade de aumentar a velocidade de uma reação química sem alterar a energia de Gibbs padrão na reação $\left(\Delta \mathrm{G}_{\mathrm{r}}{ }^{\circ}\right){ }^{7}$ Os catalisadores permitem que as reações tenham um mecanismo alternativo, mais rápido que aquele que ocorre em sua ausência. Assim, embora o catalisador participe do mecanismo reacional, ao final do ciclo reacional ele é regenerado. ${ }^{8} \mathrm{Em}$ princípio, o catalisador não seria consumido ao final de um ciclo catalítico, entretanto, reações adicionais, a presença de venenos ou condições operacionais podem levar à perda de atividade catalítica. ${ }^{9}$ As principais classificações de catalisadores atualmente são: homogêneos, enzimáticos e heterogêneos. Já a ciência que estuda os fenômenos que ocorrem a partir da utilização de catalisadores em reações químicas é chamada de catálise. ${ }^{7}$

Até o século XVIII, a catálise se concentrava na produção de bebidas e alimentos, através da catálise biológica ou enzimática. Aqui é importante mencionar que a catálise ocorre na natureza desde o surgimento da vida, a partir de processos bioquímicos de digestão,

*e-mail: tmlima@id.uff.br;

\#e-mail alternativo: fabiopassos@id.uff.br fermentação e respiração, entre outros processos intrínsecos dos seres vivos. Foi a partir de meados do século XVIII que os primeiros catalisadores (homogêneos e heterogêneos) passaram a ser utilizados em processos químicos industriais, como a produção sintética de $\mathrm{H}_{2} \mathrm{SO}_{4}$ pelo processo de câmara de $\mathrm{Pb}$ com $\mathrm{NO}_{2}$ como catalisador em 1746, pelo processo de contato em 1831 por oxidação do $\mathrm{SO}_{2}$ catalisada por $\mathrm{V}_{2} \mathrm{O}_{5} \mathrm{ou} \mathrm{Pt}$ ), a fabricação de gás $\mathrm{Cl}_{2}$ por oxidação de $\mathrm{HCl}$ sobre $\mathrm{CuCl}_{2}$ (processo Deacon, 1875), a oxidação de $\mathrm{NH}_{3}$ a $\mathrm{HNO}_{3}$ na presença de telas de $\mathrm{Pt}$ (1904), e a síntese $\mathrm{NH}_{3}$ a partir de $\mathrm{N}_{2}$ e $\mathrm{H}_{2}$ catalisada por $\mathrm{Fe}$ (1910). ${ }^{10,11}$

A catálise é a tecnologia mais utilizada na indústria química desde a segunda revolução industrial, sendo responsável por cerca de $70 \%$ dos processos industriais modernos e por $80 \%$ dos produtos de valor agregado. O valor atual de todos dos catalisadores disponíveis superou os 17 bilhões de dólares no ano de 2018.,12-16 Desta forma, podemos dizer que a catálise exerce um papel fundamental em diversos processos como remediação ambiental, produção de combustíveis e refino do petróleo, síntese de produtos para química fina, na indústria farmacêutica, de polímeros e alimentícia. Além disso, do ponto de vista sustentável, a catálise também atende aos princípios da Química Verde, permitindo a obtenção de produtos com menores tempos reacionais ou mesmo levar a produtos que termicamente não seriam favorecidos. A Figura 1 apresenta um comparativo entre os processos industriais que utilizam catálise e quais tipos são empregados. ${ }^{1-6}$

A produção de um catalisador que, por exemplo, possua as vantagens de um catalisador homogêneo e heterogêneo de forma simultânea sempre despertou interesse e se tornou um desafio durante décadas. ${ }^{17-19}$ Catalisadores heterogêneos que usam metais em escalas nanométricas dispersos em suportes têm sido bastante estudados nos últimos anos e vêm atendendo os quesitos tão almejados por grande parte dos processos, como alta eficiência, menor custo (pela menor quantidade de metais utilizados em sua composição), ajuste de seletividade a diferentes produtos e reuso. ${ }^{20}$ Entretanto, apesar destes apresentarem maiores atividades, ainda frequentemente apresentam baixa exposição de sítios ativos. Assim, a catálise por átomos isolados 


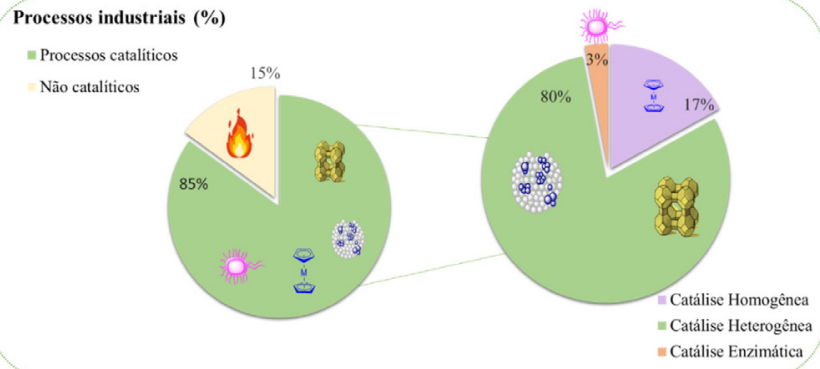

Figura 1. Distribuição percentual dos processos industriais que utilizam catálise e suas respectivas frações dentro destes processos

(do termo em inglês single-atom catalysis), que une as vantagens da catálise heterogênea e homogênea, representou um grande avanço científico-industrial e tem mudado constantemente o projeto de novos catalisadores para processos industriais já conhecidos. A Figura 2 apresenta um gráfico com a evolução do número de publicações referentes a catalisadores de átomos isolados e ligas de átomos isolados (single-atom alloys) que também serão abordadas nessa revisão.

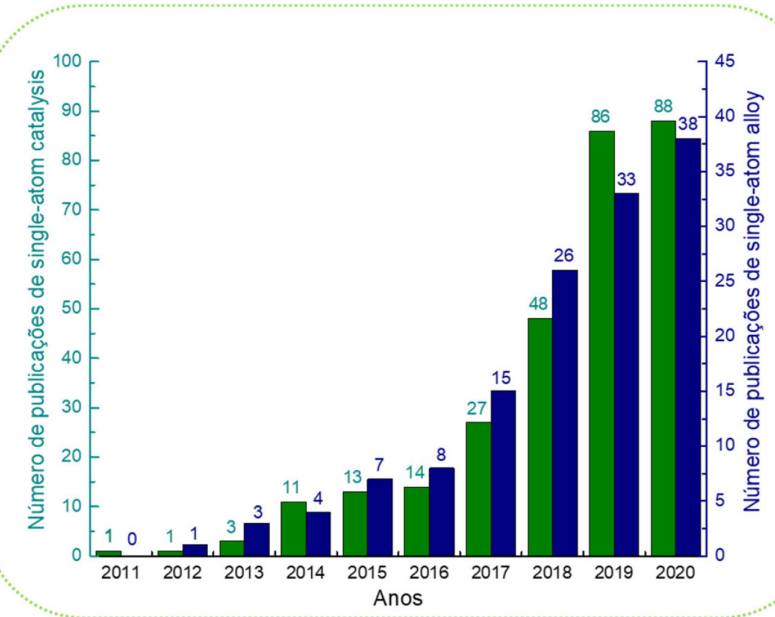

Figura 2. Evolução do número de publicações envolvendo os termos single-atom catalysis e single-atom alloy obtido na plataforma Web of Science ${ }^{\circledR}$

Os catalisadores de átomos isolados têm sido amplamente empregados, em diversos campos da catálise em escala laboratorial, principalmente por conta de vantagens como: (i) $100 \%$ de utilização atômica da fase ativa, levando à altas eficiências catalíticas; (ii) sítios ativos uniformes, levando a seletividades exclusivamente dependentes do mecanismo reacional; (iii) baixo número de coordenação dos sítios ativos, levando a adsorções mais fortes e atividades catalíticas maiores. ${ }^{21}$ Entretanto, apesar de diversas vantagens associadas aos catalisadores de átomos isolados, é preciso mencionar que diversos desafios precisam ser ainda superados, como a estabilidade destes em condições reacionais mais drásticas. ${ }^{21}$

Neste contexto, esta revisão focará nos principais avanços da catálise por átomos isolados, abordando vantagens e dificuldades, além de métodos de preparação e principais aplicações. Entretanto, antes de entrarmos no tema específico, faremos uma breve revisão da classificação dos tipos de catálise tradicionalmente utilizada na literatura científica, apresentando os principais fundamentos e exemplos de reações.

\section{CATÁLISE HOMOGÊNEA}

Na catálise homogênea, os catalisadores e os reagentes estão na mesma fase, normalmente em fase líquida. Por este motivo, o catalisador encontra-se disperso em níveis atômicos durante a reação química de forma que todos os átomos do catalisador atuam como sítios ativos para a reação. Como consequência, os catalisadores homogêneos apresentam uma maior interação com os reagentes, levando a um alto rendimento das reações sem a necessidade de serem utilizadas grandes quantidades destes e permitindo também que a reação seja realizada em condições mais amenas.,

Além disso, catalisadores homogêneos também apresentam a vantagem de controlar a seletividade da reação, podendo ser quimiosseletivos ou estereosseletivos. Catalisadores quimiosseletivos reagem preferencialmente com um dos grupos funcionais da molécula mantendo os outros inalterados, ou ainda promovem preferencialmente um tipo de reação em detrimento de outra no mesmo grupo funcional, de forma que haverá a formação preferencial de um dado produto. Já catalisadores estereosseletivos ou estereoespecíficos levam à formação preferencial de um enantiômero ou diastereoisômero em relação a outro ${ }^{2,22}$ como exemplificado no Esquema 1a.

A alta seletividade, junto ao alto rendimento são os principais fatores que possibilitam o uso da catálise homogênea em escala industrial. ${ }^{2,22}$ Outra vantagem referente ao catalisador e os reagentes se encontrarem na mesma fase está relacionada à transferência de massa. O fenômeno de difusão ocorre quando, em uma solução, as moléculas são transportadas de zonas mais concentradas para as menos concentradas, de forma a se alcançar a homogeneidade da solução. Esse fenômeno ocorre sem dificuldades em fase homogênea, mas isto pode representar um grande empecilho na catálise heterogênea. Quando comparados aos catalisadores heterogêneos, os catalisadores homogêneos também apresentam a vantagem de serem menos afetados pelo envenenamento de forma geral, como por exemplo, por compostos sulfurosos..$^{2,24}$

Por outro lado, os catalisadores homogêneos possuem várias desvantagens. Devido à sua grande interação com os componentes do sistema, a recuperação do catalisador e a separação do produto são mais difíceis, sendo necessária a utilização de processos de separação que aumentam o custo do produto final. Além disso, devido à sua baixa estabilidade térmica (em que a temperatura máxima de atuação é próxima dos $250{ }^{\circ} \mathrm{C}$ ), os processos de separação podem causar danos ao catalisador utilizado. A operação em fase líquida limita a faixa de temperatura e pressão que pode ser utilizada na operação industrial. Esses fatores, bem como a larga geração de rejeito limitam o uso industrial da catálise homogênea, correspondendo a cerca de $15 \%$ dos processos catalíticos industriais. ${ }^{2,24}$

Apesar da menor aplicabilidade, alguns processos de grande importância industrial que utilizam ácidos, bases, complexos metálicos ou organometálicos como catalisadores são encontrados, conforme disposto no Esquema 1. Na indústria, uma das principais funções dos catalisadores homogêneos está relacionada a produção de combustíveis, polímeros e química fina. ${ }^{25-27}$

Nos exemplos citados no Esquema 1, notamos a presença de diversas reações de importância industrial e catalisada utilizando uma estratégia de catálise homogênea. No Esquema $1 \mathrm{~b}$ temos a reação de transesterificação de ácidos graxos para produção de biodiesel e que utilizam frequentemente ácidos como o p-toluenossulfônico e bases como carbonato de potássio, hidróxido de sódio ou hidróxido de potássio como catalisadores homogêneos. ${ }^{30,31} \mathrm{~A}$ reação do Esquema 1c é de suma importância para produção do ácido acético e industrialmente utilizado pela Monsanto ${ }^{\circledR}$ e BASF ${ }^{\circledR}$, empregando os catalisadores de $\left[\mathrm{Rh}(\mathrm{CO})_{2} \mathrm{I}_{2}\right]$ (Monsanto) ou o $\mathrm{Co}_{2}(\mathrm{CO})_{8} / \mathrm{HI}$ (BASF). ${ }^{28,32}$ Além disso, no Esquema 1d também é apresentada a reação de hidroformilação de alcenos, catalisada por $\left[\mathrm{Co}_{2}(\mathrm{CO})_{8}\right]$ que visa a formação de aldeídos com um átomo de $\mathrm{C}$ a mais em seu esqueleto quando comparado ao substrato de partida. ${ }^{29}$ 


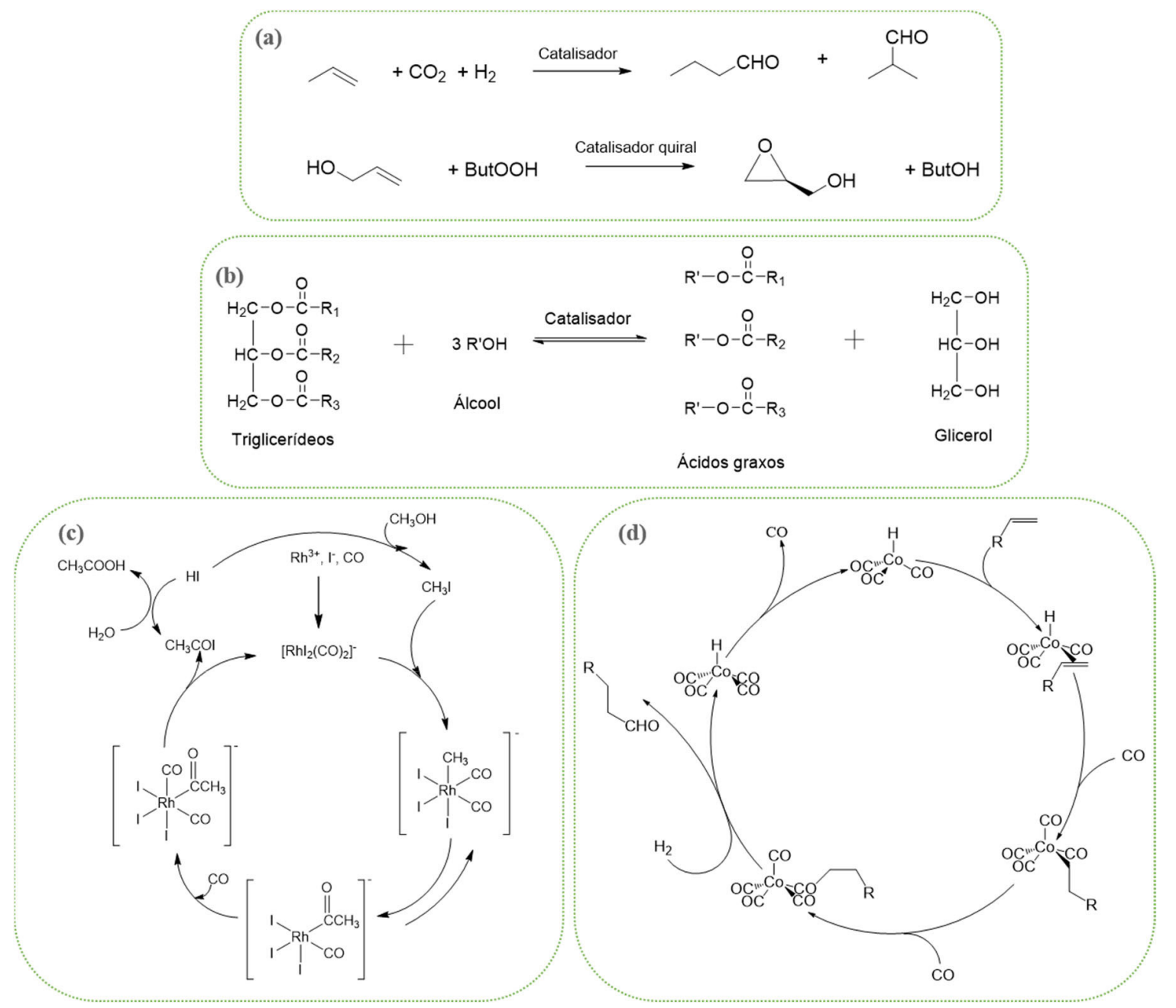

Esquema 1. Exemplos de reações que utilizam catálise homogênea: (a) reação de hidrogenação quimiosseletiva e reação estereosseletiva de formação de epóxido ${ }^{2}$ (b) reação de transesterificação em meio alcoólico ${ }^{26}\left(\right.$ c) processo de produção do ácido acético utilizando $\left[\mathrm{Rh}(\mathrm{CO})_{2} \mathrm{I}_{2}\right]$ como catalisador; ${ }^{28}(\mathrm{~d})$ processo de hidroformilação de alcenos catalisado por $\left[\mathrm{Co}_{2}(\mathrm{CO})_{8}\right]^{29}$

Ainda neste contexto, como mencionado anteriormente, a catálise homogênea também encontra aplicação essencial na síntese de produtos de química fina via catálise assimétrica. Um importante exemplo é a síntese do L-DOPA, um aminoácido utilizado no tratamento do mal de Parkinson, e que utiliza uma fosfina quiral (R,R)-DIPAMP ligada a um centro metálico de rutênio e que confere o enriquecimento preferencial de um dos enantiômeros desejados (Figura 3). ${ }^{33}$

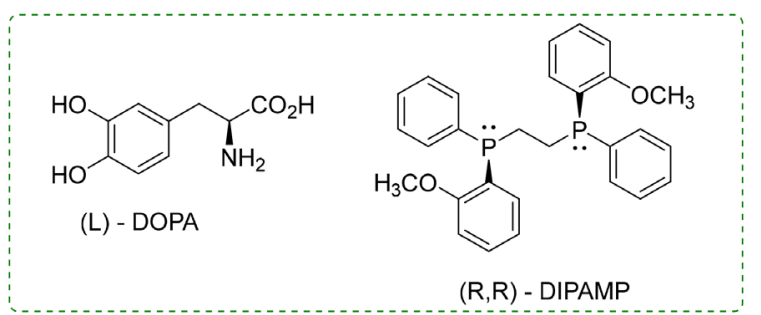

Figura 3. Estrutura das moléculas (S)-DOPA e do ligante $(R, R)$-DIPAMP $P^{33}$

\section{CATÁLISE ENZIMÁTICA}

A utilização de biocatalisadores enzimáticos apresenta diversas vantagens. Além da estereosseletividade e da alta especificidade, as enzimas são biodegradáveis, atóxicas e são utilizadas em pequena quantidade. Além disso, as reações enzimáticas são realizadas sob pressão atmosférica e temperatura ambiente, condições amenas e que possuem um impacto econômico positivo. Estes fatores levam a uma reduzida geração de rejeito, dando origem a processos mais sustentáveis. ${ }^{34,35}$

Outra vantagem está relacionada com a possibilidade de otimização das características do catalisador por meio da bioengenharia das proteínas, tanto a partir das descobertas que ocorrem na natureza, como utilizando enzimas já existentes em diferentes substratos, ou ainda através da combinação de enzimas com centros metálicos, para a formação de metaloenzimas - aumentando a seletividade e a atividade do catalisador para uma dada reação..$^{35,36}$

Por outro lado, os biocatalisadores apresentam desvantagens, pois possuem baixa estabilidade (os processos biocatalíticos necessitam de um alto controle de temperatura e $\mathrm{pH}$, além de rígido controle de presença de impurezas e contaminantes biológicos) e, ao término da reação, são difíceis de serem recuperados do meio reacional, o que leva a um aumento do custo desse processo, além de dificultar a sua reutilização. Tais obstáculos refletem em sua menor aplicação em processos industriais, cerca de 3\%. Para solucionar esse problema, foram desenvolvidas técnicas para a imobilização das enzimas em suportes, que levam ao aumento da estabilidade térmica e permitem a fácil recuperação das enzimas, mantendo sua atividade catalítica, possibilitando sua utilização em diversos ciclos reacionais. $\mathrm{O}$ suporte também possui a característica de proteger a enzima do meio reacional, evitando a desnaturação das proteínas e permitindo o uso prolongado das enzimas..$^{34,37,38}$ 
A alta performance dos biocatalisadores quando comparados a catalisadores homogêneos e heterogêneos pode ser explicada por alguns fatores que são característicos da catálise enzimática. Em primeiro lugar, a alta especificidade dos sítios catalíticos permite que os reagentes permaneçam na orientação correta, o que aumenta a probabilidade de ocorrência de colisões efetivas (colisões que levam à ocorrência da reação). Também devido à sua estrutura, as ligações da molécula ligada a enzima sofrem uma distorção, o que aumenta a energia interna e diminui a energia de ativação da reação. ${ }^{39}$ A catálise enzimática situa-se numa posição intermediária entre a catálise homogênea e a heterogênea. As enzimas são macromoléculas de proteína em tamanho coloidal. Estão na mesma fase que os reagentes, mas são grandes o suficiente para considerar sítios sobre a sua superfície.

Por fim, a mudança na conformação estrutural do sistema enzima-substrato leva à diminuição da entropia, o que leva a uma mudança na atividade da enzima. Esses fatores contribuem para que as enzimas apresentem altas taxas de conversão e formem produtos estereoespecíficos. ${ }^{39,40}$

Um exemplo de um processo industrial que utiliza biocatálise é a síntese do fármaco montelukast sodium (Singulair), utilizado para tratamento de asma, conforme apresentado no Esquema 2a. Nesse processo há a utilização de uma ceto redutase altamente seletiva na conversão de uma cetona em álcool - uma etapa essencial para a síntese do fármaco em um processo econômico e ambientalmente amigável, alcançando um rendimento acima de $95 \%$ para o enantiômero desejado. ${ }^{41}$

A utilização de tecidos frescos de plantas bem como organismos celulares ou multicelulares como catalisadores enzimáticos também vem se mostrando promissora, de forma que diversos estudos foram publicados nesta área. Cepas de Pseudomonas aeruginosa imobilizadas em alginato de sódio foram utilizadas para a conversão estereosseletiva de 2-fenil-2-aminoacetonitrila em D-fenilglicina, Esquema $2 b^{42}$ De forma similar, a biocatálise também pode ser utilizada para conversão quimioseletiva de substratos ${ }^{43}$ que utilizaram células de Saccharomyces cerevisiae como biocatalisador para a conversão de (1E,4E)-1,5-bis(4-metoxifenil)-1,4-pentadien-3-ona na 1,5-bis(4-metoxifenil)-3-pentanona, Esquema 2c. Nesse contexto, a biocatálise apresenta grande potencial em processos industriais, uma vez que se apresenta como uma alternativa sustentável, com baixa geração de rejeito quando comparadas as reações onde se utilizam catalisadores homogêneos e heterogêneos.

\section{CATÁLISE HETEROGÊNEA}

Embora os catalisadores homogêneos e enzimáticos apresentem bons desempenhos catalíticos em boa parte dos casos, o seu escalonamento para proporções industriais pode se tornar um problema a ser considerado, isso porque uma vez solúvel no meio reacional, a recuperação é difícil e dispendiosa, tornando-se, às vezes, inviável. ${ }^{16}$ Além disso, esses catalisadores necessitam de um controle mais rigoroso das condições do processo, pois, em muitos casos, possuem menores estabilidades, prejudicando assim as suas atividades e seletividades. ${ }^{16}$

Neste contexto, os catalisadores heterogêneos mostram-se como uma excelente alternativa para diversas aplicações industriais (cerca de $80 \%$ dos processos), uma vez que não são solubilizados no meio reacional, o que torna a sua recuperação e reutilização mais fácil. ${ }^{16,45}$ Podemos citar o uso de catalisadores heterogêneos em processos de hidrogenação e craqueamento na indústria do petróleo, em conversão de biomassa em produtos de maior valor agregado, na indústria de processamento da cana de açúcar, obtenção de amônia, catalisadores automotivos para redução de gases tóxicos e petroquímica em geral. ${ }^{45-47}$

De maneira geral, esses catalisadores são materiais sólidos em cuja superfície a reação ocorre. Entretanto, a superfície não é uniforme e a reação se dá em sítios ou centros ativos. A catálise heterogênea está intimamente condicionada aos fenômenos de transporte e de superfície, em especial, a difusão, a adsorção e a dessorção das moléculas nesses sítios ativos. ${ }^{45}$ Classicamente, o ciclo de catálise heterogênea é dividido em sete etapas fundamentais: ${ }^{1}$

1) Difusão externa das moléculas dos reagentes do seio do fluido até a superfície externa do grão de catalisador;

2) Difusão interna das moléculas dos reagentes da superfície externa da partícula para a superfície interna dos poros e canais presentes no grão do catalisador;

3) Adsorção das moléculas dos reagentes nos sítios ativos localizados na superfície interna do catalisador;

4) Reação química que ocorre nos sítios ativos da superfície do catalisador, convertendo as moléculas adsorvidas dos reagentes em intermediários e produtos adsorvidos;

5) Dessorção dos produtos dos sítios ativos da superfície do catalisador;

6) Difusão interna das moléculas dos produtos através dos poros e canais presentes no grão do catalisador até a superfície externa do grão de catalisador;
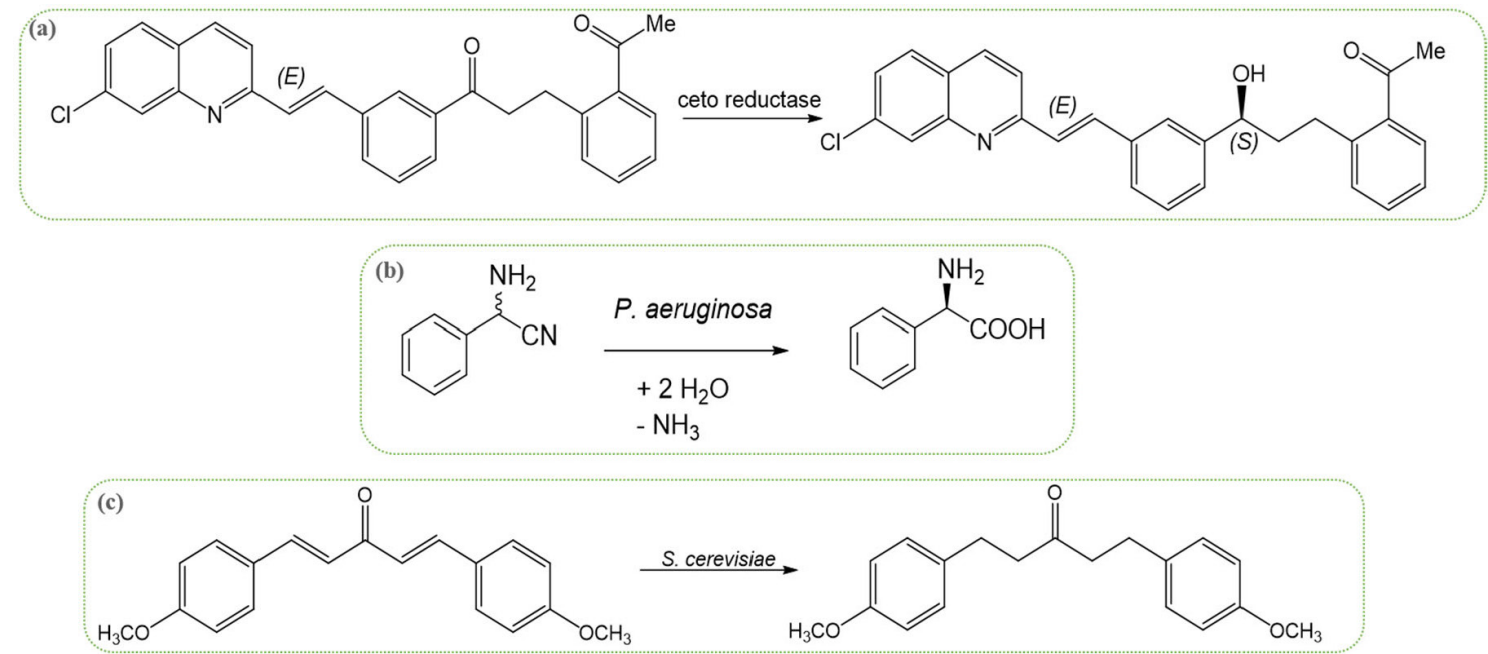

Esquema 2. Exemplos de reações que utilizam biocatálise: (a) Etapa de conversão estereosseletiva da produção de Singulair; ${ }^{44}$ (b) Conversão de 2-fenil-2-aminoacetonitrila em D-fenilglicina catalisada por Pseudomonas aeruginosa ${ }^{42}$ (c) Conversão quimiosseletiva catalisada por Saccharomyces cerevisiae ${ }^{43}$ 
7) Difusão externa das moléculas do produto da superfície externa do grão de catalisador para o seio do fluido.

As etapas da catálise heterogênea estão esquematizadas na Figura 4.

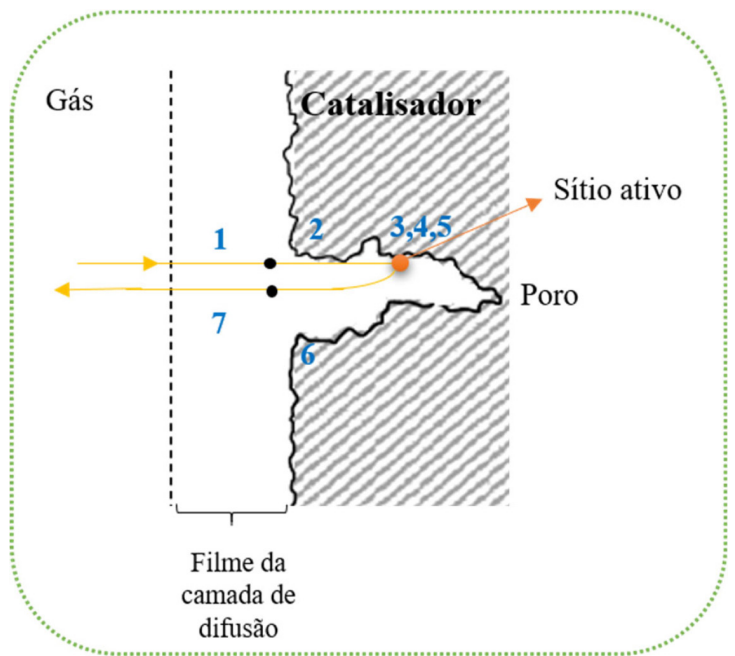

Figura 4. Etapas fundamentais de um processo catalítico sobre um catalisador heterogêneo ${ }^{48}$

A difusão externa é fortemente influenciada pela velocidade de escoamento do fluido em volta do grão com consequente variação do coeficiente de transferência de massa. A etapa de difusão interna é influenciada pelo tamanho do grão, dimensões dos poros e propriedades de difusão da mistura reacional. As etapas de transferência de massa interna e externa são processos de natureza física, enquanto as etapas de adsorção/dessorção e reação na superfície dependem da interação química entre reagentes e sítios ativos na superfície. ${ }^{48} \mathrm{~A}$ velocidade global do processo catalítico é influenciada pela relação entre as etapas de transferência de massa e as etapas de adsorção e reação na superfície. Utilizando-se o conceito de etapa limitante ou determinante da reação, a velocidade global de reação é igual à da etapa mais lenta do processo. Por exemplo, a adsorção e reação na superfície são mais fortemente influenciadas pela temperatura que as etapas de transferência de massa. Consequentemente, um aumento de temperatura pode alterar a etapa limitante do ciclo catalítico. Há também que se considerar, efeitos de resistência à transferência de calor sobre o ciclo catalítico. Adicionalmente, vale mencionar que a acessibilidade dos sítios ativos na superfície do catalisador é maior em materiais que possuem altos valores de área específica, tornando tal característica desejável em um catalisador heterogêneo. ${ }^{1,45}$

Dumesic e colaboradores ${ }^{1}$ descreveram quatro atributos essenciais para que um catalisador heterogêneo seja eficiente em um determinado processo:

- O catalisador deve apresentar uma boa seletividade para o produto desejado em questão, evitando a formação de produtos que não são interessantes para o processo;

- O catalisador deve apresentar boas taxas de conversão nas condições estabelecidas para o processo reacional;

- O catalisador deve ser estável no meio por diversos ciclos reacionais. Além disso, a sua recuperação e reativação de seus sítios ativos podem ser possíveis através de tratamentos adequados (por exemplo: lavagem e calcinação);

- Os sítios ativos do catalisador devem ser acessíveis, permitindo a difusão de moléculas dos reagentes e dos produtos, resultando em alta conversão.

Partindo desses princípios, a escolha de candidatos a catalisadores heterogêneos para diferentes processos reacionais se torna mais restrita. Os catalisadores heterogêneos podem ser classificados em catalisadores mássicos ou suportados. Os catalisadores mássicos contêm essencialmente o composto que age como catalisador (fase ativa). Nos catalisadores suportados, a fase ativa é depositada na superfície de um suporte, tradicionalmente um óxido cerâmico. $\mathrm{O}$ objetivo de suportar a fase ativa é maximizar a quantidade de sítios ativos na superfície do catalisador. ${ }^{45}$ Nesse aspecto, os materiais nanoestruturados, como o grafeno e seus derivados, ${ }^{49}$ nanopartículas metálicas, ${ }^{50}$ óxidos metálicos, ${ }^{51}$ e sílicas porosas ${ }^{52}$ ganharam destaque como suportes, por conta da sua alta área específica e possibilidade de inserção de diferentes sítios ativos. Já dentre os sítios ativos, eles podem ser divididos em três grandes grupos: sítios ácido-base, sítios metálicos e sítios de óxidos metálicos. ${ }^{45}$

Os sítios com características ácido-base são extremamente importantes em diferentes processos catalíticos, e são aplicáveis em diferentes tipos de reação desde conversão de biomassa até processos de polimerização. ${ }^{47,51} \mathrm{Um}$ exemplo clássico é o craqueamento catalítico, utilizado amplamente na indústria de petróleo e que pode ser catalisado por zeólitas ${ }^{51}$ que possuem diferentes tipos de sítios ácidos. Esses sítios podem ser sítios ácidos de Lewis, compostos por diferentes metais com orbitais d capazes de aceitar elétrons, ou sítios ácidos de BrØnsted que contém diferentes estruturas portadoras de hidrogênio ácido que pode ser doado ao meio. ${ }^{1,53}$

Os sítios metálicos também são amplamente utilizados, principalmente em reações de hidrogenação, conversão de monóxido de carbono em dióxido de carbono, dentre outros processos como hidrogenólise, desidrogenação, descarbonilação e descarboxilação. ${ }^{54}$ Alguns aspectos importantes na estrutura cristalina desses metais influenciam na sua performance como catalisadores, por exemplo, a distância interatômica, possíveis defeitos superficiais e a o plano cristalino que está exposto a superfície., ${ }^{1,45}$

Já os sítios ativos oriundos de óxidos metálicos são extensamente aplicados em processos como oxidação seletiva, isomerização, desidrogenação de alcanos, síntese de polímeros, síntese de metanol, valorização de moléculas oriundas do petróleo e reações catalisadas por sítios ácidos (isomerização, craqueamento, alquilação de aromáticos, síntese do ácido metacrílico). ${ }^{55,56}$ Nesse contexto, os íons óxido $\left(\mathrm{O}^{2-}\right)$ presentes na superfície do catalisador podem atuar ativamente na reação a ser catalisada, gerando diferentes vacâncias no sólido e defeitos eletrostáticos que irão influenciar diretamente na atividade final do catalisador e do produto desejado. ${ }^{45}$ A Figura 5 ilustra o processo de oxidação do $\mathrm{CO}$ catalisada por um óxido metálico genérico, onde os íons óxido desempenham um papel fundamental na atividade do catalisador. ${ }^{53}$ Além dos catalisadores mencionados, vale citar também a grande importância dos sulfetos metálicos como, por exemplo $\mathrm{MoS}_{2}, \mathrm{Co}_{9} \mathrm{~S}_{8}, \mathrm{WS}_{2}$, NiS e $\mathrm{RuS}_{2}$ (comumente suportados em alumina, sílica-alumina e sílicas mesoporosas). Esses materiais são eficientes catalisadores em reações de hidrodessulfurização,

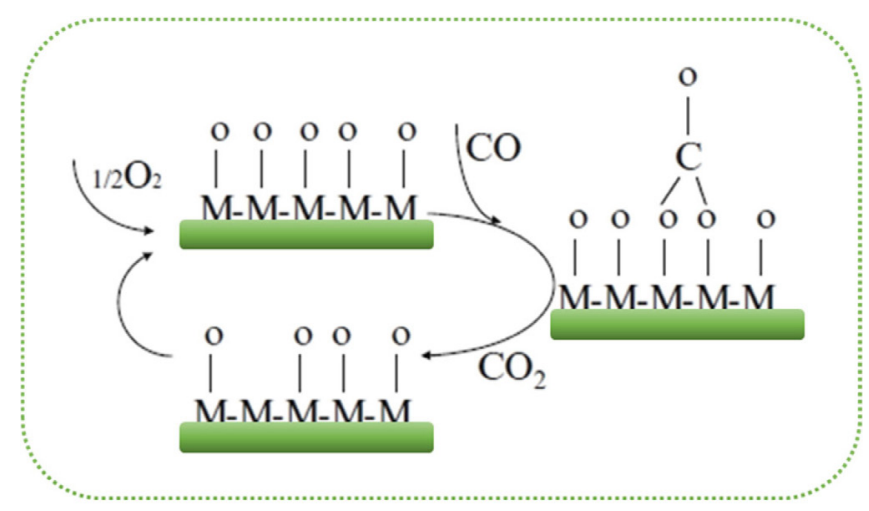

Figura 5. Mecanismo de oxidação do CO na superfície de um óxido metálico 
que visam reduzir o teor de enxofre no diesel por meio de reações de hidrotratamento. ${ }^{57}$ Adicionalmente, esses catalisadores também encontram aplicações em reações de desidrogenação e reação de redução do oxigênio. ${ }^{58,59}$

Combinar suportes e sítios ativos de diferentes tipos tem sido um grande desafio no desenho de novos catalisadores heterogêneos. Para otimizar essas condições, o avanço no conhecimento de fenômenos de superfície, caracterizações destas superfícies, dados termodinâmicos e cinéticos das reações envolvidas são essenciais. Por isso, essa área abre possibilidades de diferentes estudos interdisciplinares que incluem desde a ciência de materiais até a química teórica. ${ }^{1,16}$ Tornase essencial avaliar como tais materiais se comportam nas condições de temperatura e pressão que foram previamente otimizadas para a reação, em relação à adsorção, difusão e a própria atividade e estabilidade dos sítios ativos. Ainda, é necessário considerar fatores de desativação destes materiais como consequência da própria reação a ser catalisada, como a formação de coque, sinterização, lixiviação e envenenamento causado por diferentes espécies..$^{51,60}$

Por possuírem menor quantidade de sítios ativos expostos por unidade de massa, os catalisadores heterogêneos possuem menores atividades quando comparados aos sistemas homogêneos. Estes últimos possuem maior mobilidade no meio reacional, o que resulta em mais colisões das moléculas reagentes com os sítios ativos, que podem ser alcançados de qualquer direção. ${ }^{48}$ Já nos sistemas heterogêneos há a necessidade da difusão ao longo do sólido, conforme já mencionado, e, além disso, estima-se que menos de $20 \%$ da quantidade total de fase ativa esteja potencialmente exposta e atue como sítios ativos. ${ }^{14} \mathrm{~A}$ Tabela 1 resume as principais características da catálise homogênea e heterogênea. ${ }^{48}$

Tabela 1. Comparação das principais características da catálise homogênea e heterogênea ${ }^{48}$

\begin{tabular}{|c|c|c|}
\hline & Homogêneo & Heterogêneo \\
\hline Sítios ativos & Todos os átomos & $\begin{array}{l}\text { Somente átomos } \\
\text { superficiais }\end{array}$ \\
\hline Concentração & Baixa & Alta \\
\hline Seletividade & Alta & Menor \\
\hline Problemas de difusão & Quase ausente & $\begin{array}{c}\text { Presente (reação } \\
\text { controlada por } \\
\text { transferência de massa) }\end{array}$ \\
\hline Condições reacionais & Brandas $\left(50\right.$ a $\left.200^{\circ} \mathrm{C}\right)$ & Severas $\left(>250^{\circ} \mathrm{C}\right)$ \\
\hline Aplicabilidade & Limitada & Ampla \\
\hline Perda de atividade & $\begin{array}{l}\text { Reação irreversível } \\
\text { com produtos; } \\
\text { envenenamento }\end{array}$ & $\begin{array}{l}\text { Sinterização de } \\
\text { cristalitos metálicos; } \\
\text { envenenamento }\end{array}$ \\
\hline Estrutura/estequiometria & Definida & Indefinida \\
\hline $\begin{array}{l}\text { Possibilidade de } \\
\text { modificação }\end{array}$ & Alta & Baixa \\
\hline Estabilidade térmica & Baixa & Alta \\
\hline Separação do catalisador & Difícil & Fácil \\
\hline $\begin{array}{l}\text { Reciclagem do } \\
\text { catalisador }\end{array}$ & Possível & Não necessária ou fácil \\
\hline $\begin{array}{c}\text { Custo associado à perda } \\
\text { de catalisador }\end{array}$ & Alta & Baixa \\
\hline
\end{tabular}

Considerando o exposto na Tabela 1, para unir as vantagens sobretudo da catálise homogênea e heterogênea, isto é, a alta exposição de sítios ativos com a praticidade e estabilidade, uma nova alternativa de catálise tem sido proposta nos últimos anos na literatura especializada: os catalisadores de átomos isolados. ${ }^{61-66} \mathrm{O}$ objetivo é aumentar a exposição de sítios até o nível atômico, maximizando o contato entre o sítio ativo e o meio reacional, o que aumentaria drasticamente a conversão do processo, quando comparada a um catalisador heterogêneo convencional, além de ter um sítio ativo mais bem definido e caracterizado. ${ }^{67} \mathrm{~A}$ catálise por átomos isolados almeja preencher uma lacuna entre os catalisadores heterogêneos e homogêneos como uma "ponte" através dos SACs ou do termo em inglês Single-Atom Catalysts. ${ }^{61-66}$

\section{CATÁLISE POR ÁTOMOS ISOLADOS}

O termo catálise por átomos isolados é muito recente e acaba de completar sua primeira década. De acordo com a literatura, o grupo de Zhang em $2011^{68}$ publicou pela primeira vez o termo single-atom catalysts para se referir à uma nova classificação de catalisador. Em seus estudos, foi desenvolvido um catalisador de platina atomicamente disperso na superfície de nanocristais de óxido de ferro $(\mathrm{FeOx})$ e aplicado na reação de oxidação de monóxido de carbono. ${ }^{68}$ Após essa primeira publicação, muitos outros autores que produziram o mesmo modelo de catalisador (atomicamente dispersos ou SACs) passaram gradativamente a usar a mesma nomenclatura. Apesar do termo ter sido cunhado há dez anos, vale aqui ressaltar que os trabalhos com catálise por átomos isolados não se restringem à essa época, uma vez que diversos trabalhos podem ser encontrados na literatura que apresentam a formação de sistemas catalíticos atomicamente dispersos. ${ }^{69-75}$

Os SACs, possuem como principal particularidade em sua estrutura espécies metálicas em escala atômica, isoladas e estabilizadas por um suporte ou por liga com outro metal. ${ }^{76}$ Assim, são capazes de oferecer de forma simultânea diversas vantagens de catalisadores homogêneos e heterogêneos, ou seja, possuem boa estabilidade térmica e fácil reutilização (como na catálise heterogênea), e ao mesmo tempo, possuem boa seletividade catalítica, alta atividade, sítios ativos altamente dispersos que podem ser quase uniformes (como na catálise homogênea). ${ }^{76}$ Diversos autores ao longo da literatura interpretam que os conceitos e as características dos SACs servem como uma ponte entre os catalisadores heterogêneos e homogêneos. ${ }^{61-64,66,77,78}$ Neste contexto, os SACs vêm encontrando uma ampla gama de aplicações na literatura, conforme resumido na Tabela 2. ${ }^{65,68,79,80}$

Os SACs possuem aspectos eletrônicos significativamente diferentes dos sistemas tradicionalmente nanométricos (nanopartículas ou clusters), o que acaba influenciando diretamente em importantes propriedades como energia livre superficial, efeitos quânticos relacionados ao tamanho, sítios coordenativamente insaturados e interações com o suporte catalítico. Nesse contexto, os SACs frequentemente apresentam atividades catalíticas superiores aos catalisadores nanométricos, além de representarem a possibilidade de diminuição da carga de catalisador e maximizar a eficiência do uso dos metais. Além disso, do ponto de vista cinético, os SACs apresentam velocidades de adsorção e dessorção diferenciadas e afetam a cinética da reação estudada de uma maneira geral. ${ }^{96}$

Um dos principais requisitos e desafio para a produção de SACs é a dispersão a nível de átomos isolados dos metais nos suportes, sem haver a aglomeração destes, antes e após as reações catalisadas. Esse fenômeno de aglomeração pode ocorrer pois a energia livre de superfície dos metais aumenta à medida que a escala das partículas diminui, conforme ilustrado na Figura $6 .{ }^{13}$ Para evitar a aglomeração, é necessário que haja um suporte que isole, apresente uma forte interação e estabilize os sítios metálicos, sem comprometer de forma negativa a atividade catalítica. ${ }^{64,13,97}$

Desta forma, é necessário levar em consideração também a forte interação metal-suporte ( ou SMSI do inglês Strong Metal-Support 
Tabela 2. Exemplos SACs relatados na literatura com suas respectivas composições e aplicações

\begin{tabular}{|c|c|c|c|}
\hline Catalisador & Suporte & Aplicação & Referência \\
\hline Cs & Zeólita X & Alquilação do tolueno com metanol; condensação aldólica e reação de Knoevenagel & 14 \\
\hline $\mathrm{Au}$ ou Pt & $\mathrm{CeO}_{2}$ & Reação de deslocamento da água & 14 \\
\hline $\mathrm{Pd}$ & $\mathrm{La}-\mathrm{Al}_{2} \mathrm{O}_{3}$ & Oxidação do monóxido de carbono & 14 \\
\hline $\mathrm{Au}$ ou $\mathrm{Pt}$ & $\mathrm{CeO}_{2}$ & Reforma a vapor do metanol & 14 \\
\hline $\mathrm{Pd}$ & $\mathrm{TiO}_{2}$ & Hidrogenação do etileno & 14 \\
\hline $\mathrm{Pt}, \mathrm{Rh}$, ou Ir & $\mathrm{TiO}_{2}$ & Oxidação preferencial do $\mathrm{CO}$ & 14 \\
\hline $\mathrm{Pt}$ & $\alpha-\mathrm{MoC}$ & Reforma a vapor do metanol & 14 \\
\hline $\mathrm{Co}, \mathrm{Fe}, \mathrm{Ni}$ ou $\mathrm{Cu}$ & Carbono dopado com $\mathrm{N}$ & Reação de evolução do hidrogênio & 14 \\
\hline Co & Grafeno dopado com $\mathrm{N}$ & Reação de evolução do hidrogênio & 14 \\
\hline Pt ou Co & $\mathrm{MoS}_{2}$ & Reação de evolução do hidrogênio & 14 \\
\hline Ir & $\mathrm{TiO}_{2}$ & Redução de $\mathrm{CO}_{2}$ & 65 \\
\hline $\mathrm{Pt}$ & $\mathrm{FeOx}$ & Oxidação de CO & 68 \\
\hline $\mathrm{Ru}$ & $\mathrm{ZrO}_{2}$ & Eletroredução de $\mathrm{N}_{2}$ em $\mathrm{NH}_{3}$ & 79 \\
\hline $\mathrm{Ru}$ & $\mathrm{ZrO}_{2}$ & Hidrogenação de ácido levulínico em $\gamma$-valerolactona & 80 \\
\hline $\mathrm{Au}$ & $\mathrm{mpg}-\mathrm{C}_{3} \mathrm{~N}_{4}$ & Oxidação de organossilanos & 81 \\
\hline $\mathrm{Pd}$ & $\mathrm{g}-\mathrm{C}_{3} \mathrm{~N}_{4}$ & Hidrogenação de 5-hidroximetil-furfural em 2,5-di-hidroximetil-tetra-hidrofurano & 82 \\
\hline Ir & $\mathrm{TiO}_{2}$ & Hidrogenação de furfural em álcool furfurílico & 83 \\
\hline $\mathrm{Rh}$ & $\mathrm{ZnO}$ & Hidroformilação de olefinas & 84,85 \\
\hline $\mathrm{Au}$ & $\mathrm{FeOx}$ & Oxidação de $\mathrm{CO}$ & 86 \\
\hline $\mathrm{Rh}$ & $\mathrm{CO}_{2}$ & Oxidação de CO & 87 \\
\hline Co & Grafeno & Hidrogenação de nitroarenos & 88 \\
\hline $\mathrm{Pd}$ & $\mathrm{TiO}_{2}$ & Hidrogenação de fenilacetileno em estireno & 89 \\
\hline $\mathrm{Pd}$ & $\mathrm{CeO}_{2}$ & Alcoxicarbonilação de iodetos de arila & 90 \\
\hline $\mathrm{Fe}$ & Carbono dopado com nitrogênio $(\mathrm{CN})$ & Hidroxilação de benzeno em fenol & 91 \\
\hline $\mathrm{Pd}$ & $\mathrm{g}-\mathrm{C}_{3} \mathrm{~N}_{4}$ & Hidrogenação de 2-metil-3-butil-2-ol & 92 \\
\hline $\mathrm{Au}-\mathrm{Ni}$ & $\gamma-\mathrm{Al}_{2} \mathrm{O}_{3}$ & Hidrogenação de ácido levulínico & 93 \\
\hline Co & $\mathrm{MoS}_{2}$ & Conversão de 4-metilfenol em tolueno & 94 \\
\hline $\mathrm{Au}$ & $\mathrm{CeO}_{2}$ & Oxidação de álcool benzílico & 95 \\
\hline
\end{tabular}

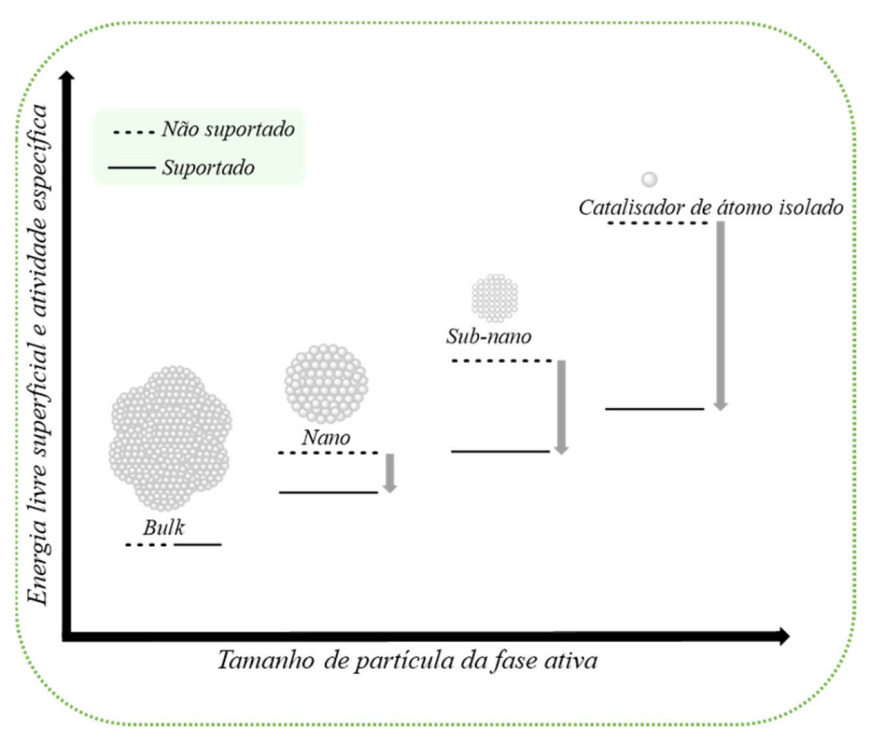

Figura 6. Energia livre superficial em função do tamanho de partícula da fase ativa ${ }^{13}$

Interaction) presente nos SACs, o que influencia diretamente na estrutura eletrônica, estabilidade, atividade catalítica e seletividade destes materiais. ${ }^{96} \mathrm{O}$ ancoramento de átomos isolados em um suporte catalítico (de caráter redutível ou não) facilita a modelagem matemática e o estudo reacional por técnicas como Teoria do Funcional da Densidade e cálculos Ab-initio. ${ }^{96,98,99}$ Ainda nesse contexto, há uma redução drástica do nível de Fermi para um átomo isolado com uma interação do tipo SMSI com o suporte, tornando os SACs excelentes candidatos a catalisadores para reações em eletrocatálise e fotocatálise. ${ }^{96}$

Adicionalmente, a escolha de um suporte adequado é de suma importância, pois ele influencia o número de coordenação, ligação química e ambiente estérico, que definem por consequência as estruturas eletrônicas e geométricas presentes nos catalisadores de átomos isolados. ${ }^{100}$ Assim, o suporte ideal para o preparo de SACs deve apresentar elevada área superficial e acoplar os sítios metálicos em escalas atômicas. ${ }^{101,102}$ Os principais suportes que vem sendo utilizados ao longo da literatura são: óxidos metálicos, zeólitas, redes metalorgânicas (MOFs), polioxometalatos e materiais bidimensionais como o grafeno, óxido de grafeno, grafino, nitreto de carbono e dissulfeto de molibdênio. ${ }^{103}$

\section{Métodos de estabilização e síntese dos SACs}

O arranjo estável entre o metal e o suporte é peça chave para se obter um catalisador de átomo isolado, e existem diferentes formas e estratégias que o suporte pode acoplar os átomos de forma isolada em sua estrutura. Dentre essas estratégias, é importante ressaltar a 
dopagem, o uso de defeitos e o confinamento espacial, conforme ilustrado na Figura 7. ${ }^{104}$

- Dopagem: é uma estratégia baseada na inserção de heteroátomos na estrutura do sólido por meio da substituição isomórfica ou mesmo em interstícios (oriundos de defeitos). Assim há a inserção de sítios de coordenação no suporte que são utilizados para o preparo do SACs. Aqui vale ressaltar como exemplo os materiais a base de carbono que são dopados com heteroátomos como $\mathrm{N}, \mathrm{O}$ e $\mathrm{S}$, e que, por possuírem pares de elétrons isolados acabam interagindo com os metais que irão compor o catalisador de átomos isolados. ${ }^{104,105}$

- Defeitos: outra tática efetiva para o isolamento estável dos átomos nos catalisadores é por meio da elaboração de defeitos na estrutura do suporte de forma controlada e uniforme. Esses defeitos acarretam a formação de sítios com coordenações insaturadas. Assim, essa estratégia é um método eficiente para ajustar a estrutura eletrônica e a morfologia da superfície do material. ${ }^{100,104}$ Os defeitos muitas vezes são aplicados nos cátions metálicos, oxigênio, enxofre e vacâncias de carbono, dependendo da natureza do suporte utilizado, que no qual irão servir como sítios de captura onde os átomos metálicos serão acoplados. ${ }^{106,107}$ Além disso, a utilização dos defeitos podem ser úteis para ajustar as características eletrônicas e ópticas dos suportes, o que permite a aplicação dos catalisadores de átomos isolados no campo da eletrocatálise e fotocatálise. ${ }^{106,108}$

- Confinamento espacial: uma estratégia de confinamento dos átomos metálicos de forma dispersa é através do encapsulamento espacial dentro da estrutura do suporte. Os materiais mais indicados para esse tipo de aprisionamento e isolamento das espécies atômicas são os porosos com tamanhos de cavidades adequados. ${ }^{108}$ Assim, os principais suportes que vem sendo utilizados e que atendem estes critérios são: zeólitas, MOFs, redes orgânicas covalentes (COFs) e nitretos de carbono grafíticos. ${ }^{104}$ Para a elaboração desse tipo de estratégia usualmente são aplicadas duas etapas de preparo, onde o primeiro passo é obter uma elevada distribuição e dispersão das espécies metálicas, separando e encapsulando os precursores do metal com o auxílio dos suportes porosos, e, em seguida, com o pós-tratamento, eliminar os ligantes presentes na espécie precursora com objetivo de obter os átomos metálicos acoplados dentro da arquitetura do suporte o que no qual garante o isolamento. ${ }^{106,108}$
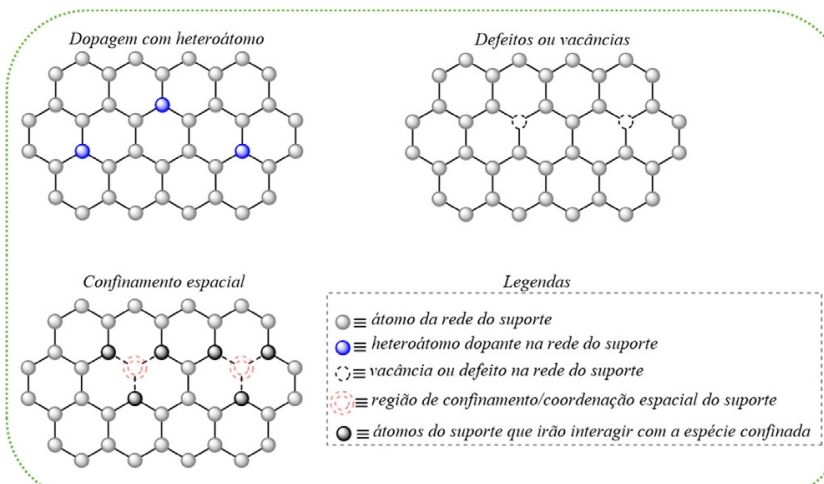

Figura 7. Abordagens para estabilização de catalisadores de átomos isolados $^{104}$

Os métodos de síntese dos SACs são classificados em métodos de síntese direta e métodos pós-sintéticos, onde na primeira categoria há a inserção do elemento em menor quantidade (a fase ativa do catalisador de átomos isolados) em posições isoladas durante a preparação do suporte adequado. A segunda categoria utiliza métodos em que o elemento em menor quantidade é inserido sobre um suporte com características específicas e já previamente preparado, conforme ilustrado na Figura 8. ${ }^{104}$

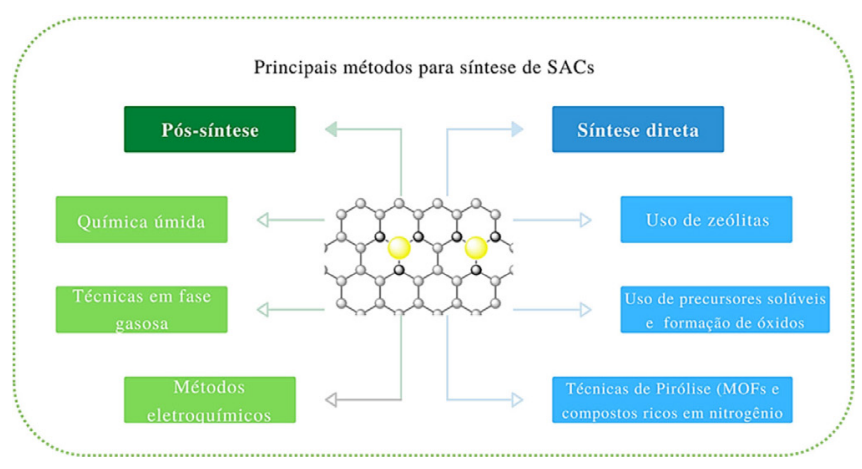

Figura 8. Principais métodos para síntese de catalisadores de átomos isolados ${ }^{104}$

Entre os métodos de síntese direta podemos citar o uso de zeólitas, argilas aniônicas ou catiônicas, materiais a base de carbono e ainda MOFs para incorporação dos átomos isolados da fase ativa do catalisador. ${ }^{104}$ Há também a possibilidade de se utilizar a co-precipitação dos precursores de interesse para preparar óxidos metálicos com sítios ativos atomicamente dispersos. Ainda, é importante citar rotas de decomposição em altas temperaturas para obtenção de catalisadores de átomos isolados compostos por materiais a base de carbono, como por exemplo, decomposição de precursores nitrogenados na presença do metal de interesse ou ainda o uso de MOFs como uma rede para inserção de metais isolados. $\mathrm{O}$ uso de MOFs para a produção de SACs tem despertado interesse pelo fato de possuírem elevada área superficial e porosidade ajustável para o encapsulamento de moléculas precursoras metálicas isoladas. Além disso, os íons metálicos podem ser isolados por ligantes orgânicos nos MOFs, que permitem a dispersão atômica de sítios metálicos no polímero. ${ }^{104}$

Os métodos pós-sintéticos fazem a introdução dos elementos em menor quantidade em suportes já previamente preparados e, para isso, fazem o uso de técnicas como química úmida, fase gasosa e métodos eletroquímicos. ${ }^{104} \mathrm{O}$ método de química úmida (do inglês wet chemistry) é amplamente utilizado para produção de SACs, devido à sua fácil operação e baixo custo. ${ }^{12}$ Os precursores metálicos utilizados, que podem ser um sal metálico ou um complexo organometálico, já contêm átomos isolados do metal e o objetivo desta técnica é inserir estas espécies metálicas nos suportes por meio de uma reação química e sem agregação. ${ }^{13,104,109}$ Essa técnica de produção consiste em três etapas principais: primeiro, o precursor metálico é introduzido no suporte por impregnação úmida, co-precipitação ou deposiçãoprecipitação; então, os materiais são secos e calcinados; e, por fim, é executada a redução ou ativação de espécies metálicas. ${ }^{110-112} \mathrm{O}$ método de química úmida pode ser aplicado em larga escala, porém utiliza pequena quantidade de espécies metálicas para a produção de SACs visando evitar a formação de aglomerados e nanopartículas. ${ }^{111}$

Diversas técnicas em fase gasosa podem ser utilizadas para o preparo pós-sintético de SACs, como por exemplo mass-selected soft-landing, deposição física de vapor, aprisionamento atômico, e o método de deposição de camada atômica (do inglês atomic layer deposition, ALD). ${ }^{104}$ Aqui o foco será dado em especial na técnica de ALD e mass-selected soft-landing por suas maiores versatilidades e aplicabilidades na literatura. ${ }^{104}$

A ALD tem a capacidade de formar filmes finos de óxido metálico com precisão atômica por meio de deposição química em fase gasosa. ${ }^{113,114} \mathrm{~A}$ produção de catalisadores de átomos isolados 
a partir desta técnica envolve as seguintes etapas: primeiro, o prétratamento térmico ou químico é aplicado ao suporte para formar locais de deposição para ALD; em seguida, os precursores metálicos são expostos ao suporte e são quimissorvidos nos locais de deposição devido ao efeito estérico. Finalmente, os ligantes orgânicos dos precursores metálicos são removidos por meio da exposição à fase gasosa. ${ }^{115}$ Essa técnica tem como principal vantagem o controle do tamanho, morfologia, densidade e quantidade de espécies metálicas, o que permite o controle da síntese de SACs com precisão, porém tem como desvantagens um alto custo de instrumentação e baixo rendimento de produção. ${ }^{109,112,113}$

A técnica de mass-selected soft-landing é uma técnica de produção de SACs que permite o controle preciso das massas e do número de espécies metálicas aplicadas aos catalisadores. Nesse método, as espécies de metal puro passam por processamento térmico em alta temperatura e, em seguida, são vaporizadas e transportadas por um gás inerte. Os materiais vaporizados passam por um filtro de massa, onde há uma seleção das espécies que serão aplicadas aos suportes por ultra-alto vácuo para a produção de SACs..$^{13,115,116}$ Essa técnica de produção é muito precisa no controle da produção dos SACs, porém, tem como desvantagem um alto custo de produção e baixo rendimento. ${ }^{13,109}$

Os métodos eletroquímicos utilizam a eletrodeposição de átomos isolados da fase ativa e, no geral, são precisos por seu aprimorado controle de voltagem e tempo de deposição. Assim, os SACs podem ser produzidos utilizando técnicas de eletrodeposição de íons metálicos dissolvidos em soluções eletrolíticas aplicadas ao suporte do catalisador. ${ }^{114} \mathrm{~A}$ taxa de deposição de íons metálicos no suporte é favorável à formação de átomos isolados, pois a difusão é lenta, e essa taxa pode ser ajustada e controlada de acordo com a concentração do precursor do íon metálico. ${ }^{12,114}$ A eletrodeposição é considerada uma técnica fácil, econômica e escalável, porém, tem a desvantagem de criar um revestimento não uniforme nos catalisadores. ${ }^{12,112}$

\section{Técnicas de caracterização de SACs}

A caracterização dos catalisadores de átomos isolados requer um conjunto de diversas técnicas de caracterização que serão complementares e formarão um quebra-cabeça de informações relacionadas entre si e, assim, confirmarão a dispersão atômica da fase ativa sobre o suporte de interesse. Assim, a Tabela 3 apresenta as principais técnicas de caracterização utilizadas em catalisadores de átomos isolados, bem como suas aplicações e limitações para estes sistemas. ${ }^{104,110,117-130}$

\section{Outros tipos de catalisadores de átomos isolados}

Além dos catalisadores de átomos isolados que estamos nos referindo até aqui como SACs, cabe ressaltar a existência de outros tipos de catalisadores baseados em sítios atômicos e que também são bastante encontrados e estudados na literatura. Assim, cabe aqui citar a existência dos catalisadores de pequenos aglomerados de átomos (do inglês Single Clusters Catalysts, SCC) e catalisadores de ligas de átomos isolados (do inglês Single Atom Alloys, SAA), conforme ilustrado na Figura 9. ${ }^{131}$

Os catalisadores do tipo SCC são obtidos quando o tamanho das nanopartículas metálicas da fase ativa decresce de nanômetros para a escala de poucos átomos, gerando clusters ou pequenos aglomerados de átomos. É comum encontrar na literatura a nomenclatura do tipo $\mathrm{M}_{\mathrm{x}}$ para os SCCs, onde $\mathrm{M}$ representa o metal da fase ativa e $\mathrm{x}$ a quantidade de átomos que constituem o aglomerado. A distância entre os átomos do aglomerado é pequena, podendo gerar um comportamento catalítico diferente dos SACs, uma vez que moléculas podem ser
Tabela 3. Principais técnicas de caracterização para SACs, aplicações e limitações para estes sistemas ${ }^{104}$

\begin{tabular}{|c|c|c|}
\hline Técnica & Aplicação & Limitação \\
\hline $\begin{array}{l}\text { Microscopia eletrônica } \\
\text { de varredura por } \\
\text { transmissão }\end{array}$ & $\begin{array}{l}\text { Observação dos átomos } \\
\text { isolados no suporte }\end{array}$ & $\begin{array}{l}\text { Região localizada, } \\
\text { necessidade de alto } \\
\text { contraste }\end{array}$ \\
\hline $\begin{array}{l}\text { Microscopia de força } \\
\text { tunelamento }\end{array}$ & $\begin{array}{l}\text { Observação dos átomos } \\
\text { isolados no suporte }\end{array}$ & $\begin{array}{l}\text { Região localizada, } \\
\text { necessidade de } \\
\text { superfície condutora }\end{array}$ \\
\hline $\begin{array}{c}\text { Espectroscopia de perda } \\
\text { de energia de elétrons } \\
\text { e espectroscopia de } \\
\text { energia dispersiva de } \\
\text { raios X }\end{array}$ & Análise elementar & $\begin{array}{l}\text { Interferência oriunda do } \\
\text { suporte utilizado }\end{array}$ \\
\hline $\begin{array}{l}\text { Espectroscopia de } \\
\text { absorção de raios } X\end{array}$ & $\begin{array}{l}\text { Ambiente químico de } \\
\text { coordenação e estados } \\
\text { eletrônicos }\end{array}$ & $\begin{array}{l}\text { Fornece uma média } \\
\text { destas características }\end{array}$ \\
\hline $\begin{array}{c}\text { Espectroscopia de } \\
\text { fotoelétrons excitados } \\
\text { por raios X }\end{array}$ & $\begin{array}{l}\text { Composição elementar, } \\
\text { estados de oxidação das } \\
\text { espécies presentes na } \\
\text { superfície }\end{array}$ & $\begin{array}{c}\text { Referências adequadas } \\
\text { que levam em conta os } \\
\text { efeitos dos ambientes } \\
\text { químicos }\end{array}$ \\
\hline Difração de raios X & $\begin{array}{c}\text { Detecção de } \\
\text { nanopartículas metálicas } \\
\text { maiores que } 2 \mathrm{~nm}\end{array}$ & $\begin{array}{l}\text { Não adequada para } \\
\text { distinguir entre } \\
\text { átomos isolados de } \\
\text { nanopartículas pequenas }\end{array}$ \\
\hline $\begin{array}{l}\text { Espectroscopia na região } \\
\text { do infravermelho usando } \\
\text { transformada de Fourier }\end{array}$ & $\begin{array}{l}\text { Distinguir modos } \\
\text { vibracionais de } \\
\text { moléculas sonda } \\
\text { adsorvidas em } \\
\text { átomos isolados e em } \\
\text { nanopartículas }\end{array}$ & $\begin{array}{c}\text { Limitada a determinadas } \\
\text { combinações de átomos } \\
\text { isolados e suportes } \\
\text { (ex. não adequado para } \\
\text { sistemas a base de } \\
\text { carbono) }\end{array}$ \\
\hline Espectroscopia Raman & $\begin{array}{l}\text { Regiões de fingerprints } \\
\text { estruturais e interação } \\
\text { entre metal e suporte }\end{array}$ & $\begin{array}{l}\text { Não aplicável para } \\
\text { suportes fluorescentes }\end{array}$ \\
\hline $\begin{array}{c}\text { Ressonância Magnética } \\
\text { Nuclear }\end{array}$ & Ambiente químico & $\begin{array}{c}\text { Requer altas } \\
\text { concentrações de metal } \\
\text { da fase ativa }\end{array}$ \\
\hline $\begin{array}{l}\text { Ressonância } \\
\text { Paramagnética } \\
\text { Eletrônica }\end{array}$ & $\begin{array}{l}\text { Identidade química } \\
\text { e estado de oxidação } \\
\text { elementar }\end{array}$ & $\begin{array}{l}\text { Requer a presença de } \\
\text { espécies com elétrons } \\
\text { desemparelhados }\end{array}$ \\
\hline $\begin{array}{l}\text { Espectroscopia } \\
\text { Mössbauer }\end{array}$ & $\begin{array}{c}\text { Simetria de coordenação, } \\
\text { estado químico e estado } \\
\text { de spin }\end{array}$ & $\begin{array}{l}\text { 'Requer elementos ativos } \\
\text { no fenômeno Mössbauer }\end{array}$ \\
\hline
\end{tabular}

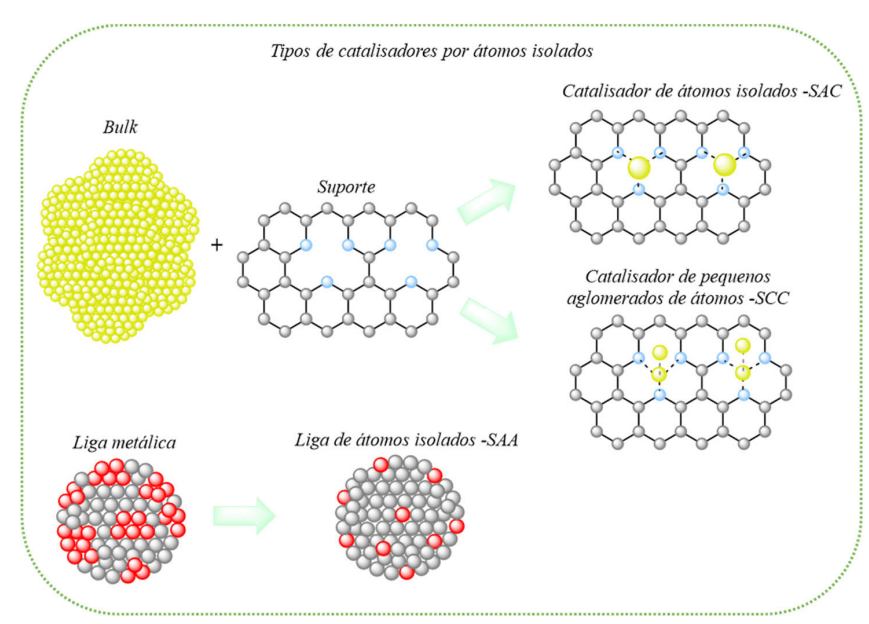

Figura 9. Ilustração dos catalisadores por átomos isolados: single-atom catalysts (SAC), single clusters catalysts (SCC) e single-atom alloys (SAA) ${ }^{131}$ 
adsorvidas em regiões próximas do catalisador. Além disso, vale mencionar que a caracterização de SCCs é mais desafiadora do que para os SACs, sendo muitas vezes necessário aliar o uso de técnicas espectroscópicas de absorção de raios X, XAS, (capaz de determinar a distância entre os átomos dos aglomerados) e microscopia eletrônica de transmissão de alta resolução. As rotas sintéticas para a obtenção dos SCCs são bastante similares às descritas anteriormente para a síntese dos SACs, sendo mais comum as técnicas de ALD, química úmida e decomposição térmica de MOFs. Nesse contexto, a Tabela 4 apresenta alguns exemplos ilustrativos dos SCCs descritas na literatura e suas composições. ${ }^{132-134}$

Tabela 4. Alguns exemplos ilustrativos do uso de SCCs encontrados na literatura e suas composições

\begin{tabular}{cccc}
\hline Catalisador & Suporte & Aplicação & Referência \\
\hline $\mathrm{Ru}_{3}$ & $\mathrm{CN}$ & Oxidação seletiva de álcoois & 135 \\
$\mathrm{Pt}_{7}$ & $\mathrm{TiO}_{2}$ & Oxidação do CO & 136 \\
$\mathrm{Pt}_{7}$ & $\mathrm{Al}_{2} \mathrm{O}_{3}$ & Desidrogenação do etileno & 137 \\
$\mathrm{Ir}_{4}$ & $\mathrm{MgO}$ & Hidrogenação de olefinas & 138 \\
$\mathrm{Ag}_{3}$ & $\mathrm{Al}_{2} \mathrm{O}_{3}$ & Epoxidação de olefinas & 139 \\
$\mathrm{Pd}_{3}$ & $\mathrm{CN}$ & Hidrogenação de alcinos & 140 \\
$\mathrm{Pd}_{10}$ & $\mathrm{Cu}-\mathrm{Nanofios}$ de Te & Reação de redução de $\mathrm{CO}_{2}$ & 141 \\
$\mathrm{Fe}_{2}$ & $\mathrm{NC}$ & Reação de redução do $\mathrm{O}_{2}$ & 142 \\
$\mathrm{Fe}_{3}$ & $\mathrm{Al}_{2} \mathrm{O}_{3}$ & Síntese da amônia & 143 \\
\hline
\end{tabular}

Em 2012 o grupo de Sykes e Flytzani-Stephanopoulos ${ }^{144}$ reportou a síntese e aplicação dos catalisadores baseados em ligas atômicas, ou SAAs, quando sintetizaram ligas de $\mathrm{Pd} / \mathrm{Cu}$ (111). O catalisador de liga atômica é um tipo de catalisador bimetálico de átomos isolados, onde uma pequena quantidade de um dos átomos metálicos é dispersa na superfície do outro átomo metálico, que tem o papel de suporte. Assim, o átomo metálico em menor quantidade possui estrutura eletrônica semelhante a de um átomo livre. ${ }^{144}$

Os métodos mais comuns para a síntese dos SAAs são substituição galvânica, impregnação seca, redução sequencial e outras estratégias sintéticas. Neste contexto, é importante mencionar que fatores como a concentração de precursor de metal, temperatura, solventes, uso de surfactantes e a interação entre íons metálicos e as moléculas de ligante podem interferir diretamente na dispersão do catalisador obtido. ${ }^{131}$

Os SAAs são comumente empregados em reações de hidrogenações seletivas, desidrogenações, reações de acoplamento $\mathrm{C}-\mathrm{C}$ e $\mathrm{C}-\mathrm{O}$, redução de $\mathrm{NO}$ e oxidação de $\mathrm{CO}$, entre outros. ${ }^{145}$ As pesquisas envolvendo SAAs têm sido mais direcionadas para o campo da energia sustentável como, por exemplo, tecnologias baseadas na conversão eletrocatalítica de energia e conversão de compostos orgânicos insaturados por hidrogenação catalítica. ${ }^{131,145,146}$ A Tabela 5 apresenta alguns exemplos ilustrativos do uso de SAAs e suas respectivas composições e aplicações. ${ }^{131,145}$

No caso dos SAAs, as principais vantagens são que a sua produção é favorável para um uso razoável de metais nobres, melhorando assim a eficiência da utilização atômica. Além disso, a estrutura eletrônica única do sítio ativo e a forte interação entre diferentes metais na interface dos catalisadores promovem um efeito sinérgico, proporcionando altas atividade catalítica e seletividade específica. Adicionalmente, os sítios ativos bem definidos ajudam a compreender de forma abrangente a relação entre a estrutura do catalisador e o seu desempenho. ${ }^{131}$ As limitações dos SAAs estão relacionadas à estabilidade, pois em altas temperaturas os catalisadores tendem a serem desativados devido a fenômenos de sinterização. ${ }^{145}$
Tabela 5. Alguns exemplos ilustrativos do uso de SAAs encontrados na literatura e suas composições

\begin{tabular}{cccc}
\hline Catalisador & Suporte & Aplicação & Referência \\
\hline $\mathrm{Pt}-\mathrm{Cu}$ & $\mathrm{Pd}$ & Reação de evolução de $\mathrm{H}_{2}$ & 147 \\
$\mathrm{Co}_{0,6}$ & $\mathrm{Ru}_{0,94}$ & & 148 \\
$\mathrm{Ru}$ & $\mathrm{Pt}_{3} \mathrm{Cu}$ & Reação de evolução do $\mathrm{O}_{2}$ & 149 \\
$\mathrm{Pd}$ & $\mathrm{Au}_{1-\mathrm{x}}$ & Reação de redução do $\mathrm{O}_{2}$ & 150 \\
$\mathrm{Pt}$ & $\mathrm{Au}$ & Oxidação do ácido fórmico & 151 \\
$\mathrm{Pt}$ & $\mathrm{Cu}$ & Hidrogenação seletiva & 152 \\
$\mathrm{Pd}$ & $\mathrm{Ag}$ & Hidrogenação do acetileno & 153 \\
$\mathrm{Rh}$ & $\mathrm{Co}_{\mathrm{n}}$ & Redução do NO a N & 154 \\
$\mathrm{Ni}_{0,0001} \mathrm{Cu}$ & $\mathrm{SiO}_{2}$ & Desidratação do etanol & 155 \\
$\mathrm{Pt}$ & $\mathrm{Cu}_{2}$ & Desidrogenação do ácido fórmico & 156 \\
$\mathrm{Au}$ & $\mathrm{Ti}_{2} / \mathrm{TiO}_{2}$ & Oxidação do CO & 157 \\
\hline
\end{tabular}

\section{CONSIDERAÇÕES FINAIS}

Buscamos, neste texto, fazer uma ampla abordagem dos principais conceitos de catálise já conhecidos (homogênea, heterogênea e enzimática) e trouxemos um enfoque especial para a catálise por átomos isolados, um conceito relativamente novo e que traz consigo uma ampla janela de oportunidades em diversos campos científicos-tecnológicos. Os catalisadores de átomos isolados apresentam atividades catalíticas e seletividades bastante superiores quando comparados aos tradicionais sistemas nanométricos, como consequência de suas propriedades eletrônicas e geométricas. A maximização na eficiência atômica, oriunda do caráter intrínseco destes materiais, possibilita o aumento da sustentabilidade de diversos processos, além de vislumbrar uma redução nos custos destes. Os potenciais de combinações entre átomos isolados (SACs, SCCs e SAAs) e suportes são importantes ferramentas para construção de eficientes catalisadores para um amplo escopo de reações que vão desde as tradicionais reações de conversão de moléculas oriundas do petróleo a até reações de elevado interesse na atualidade, como reações de produção de hidrogênio via eletrocatálise e conversão de moléculas orgânicas oriundas de fontes renováveis. Apesar dessa enorme versatilidade que esse novo tipo de catálise traz consigo, diversos desafios ainda precisam ser superados para sua ampla aplicação. Aqui cabe mencionar o desafio de se isolar átomos componentes da fase ativa sem ocorrer aglomeração e consequente redução de atividade, a necessidade de conhecimento aprimorado da química e física do estado sólido e técnicas de síntese, a dificuldade de caracterização desses sistemas (sendo necessárias diversas técnicas que vão desde as mais rotineiras a até as mais complexas), a dificuldade de aumento da escala de síntese desses materiais, a estabilidade em condições mais drásticas de reações (altas temperaturas e pressões), evitando a aglomeração dos átomos isolados, e, consequentemente, o reuso desses materiais em diversos ciclos reacionais.

\section{AGRADECIMENTOS}

O presente trabalho foi realizado com apoio da Coordenação de Aperfeiçoamento de Pessoal de Nível Superior - Brasil (CAPES) Código de Financiamento 001. Os autores também agradecem ao Conselho Nacional de Desenvolvimento Científico e Tecnológico (CNPq), à Fundação Carlos Chagas Filho de Amparo à Pesquisa do Estado do Rio de Janeiro (FAPERJ, processos n. E-26/210.385/2018, E-26/211.575/2019, E-26/010.000.984/2019) e ao PPGQ-UFF. 


\section{REFERÊNCIAS}

1. Dumesic, J. A.; Huber, G. W.; Boudart, M.; In Handbook of Heterogeneous Catalysis; Ertl, G.; Knözinger, H.; Schüth, F.; Weitkamp, J., Eds.; Wiley-VCH Verlag GmbH \& Co. KGaA: Weinheim, Germany, 2008; pp. 1.

2. Bhaduri, S.; Mukesh, D.; In Homogeneous Catalysis: Mechanisms and Industrial Applications, Second Edition; John Wiley \& Sons, Inc: Hoboken, NJ, 2014; pp. 1.

3. Bernardo-Gusmão, K.; Pergher, S. B. C.; dos Santos, E. N.; Quim. Nova 2017, 40, 650 .

4. Armor, J. N.; Catal. Today 2011, 163, 3.

5. Figueiredo, J. L.; Ribeiro, F. R.; Catálise Heterogênea; Catouste, F. G., Ed.; Lisboa, 1989.

6. Gonçalves, C. da C. S.; Marsaioli, A. J.; Quim. Nova 2013, 36, 1587.

7. IUPAC; In Compendium of Chemical Terminology (the "Gold Book"); A. D. McNaught and A. Wilkinson, Ed.; IUPAC: Research Triagle Park, NC; Vol. 2291, p. 2293.

8. RUSSEL, J. B.; Química Geral; Mcgraw-Hill do Brasil, 1982., Ed.; São Paulo, 1982.

9. Bartholomew, C. H.; Appl. Catal. A Gen. 2001, 212, 17.

10. Armor, J. N.; Catal. Today 2011, 163, 3.

11. Jairton Dupont; Quim. Nov. 2002, 25, 12.

12. Li, H.; Zhu, H.; Zhuang, Z.; Lu, S.; Duan, F.; Du, M.; Sustain. Energy Fuels 2020, 4, 996.

13. Yang, X.-F.; Wang, A.; Qiao, B.; Li, J.; Liu, J.; Zhang, T.; Acc. Chem. Res. 2013, 46, 1740.

14. Wang, A.; Li, J.; Zhang, T.; Nat. Rev. Chem. 2018, 2, 65.

15. Handbook of Heterogeneous Catalysis; Ertl, G.; Knözinger, H.; Schüth, F.; Weitkamp, J., Eds.; Wiley-VCH Verlag GmbH \& Co. KGaA: Weinheim, Germany, 2008.

16. Vojvodic, A.; Nørskov, J. K.; Natl. Sci. Rev. 2015, 2, 140.

17. Ji, S.; Chen, Y.; Wang, X.; Zhang, Z.; Wang, D.; Li, Y.; Chem. Rev. 2020, $120,11900$.

18. Chen, F.; Jiang, X.; Zhang, L.; Lang, R.; Qiao, B.; Chinese J. Catal. 2018, 39, 893.

19. Zhang, H.; Liu, G.; Shi, L.; Ye, J.; Adv. Energy Mater. 2018, 8, 1701343.

20. Wang, M.; Feng, B.; Li, H.; Li, H.; Chem 2019, 5, 805.

21. Chen, Z. W.; Chen, L. X.; Yang, C. C.; Jiang, Q.; J. Mater. Chem. A 2019, 7, 3492 .

22. Dias, F. R. F.; Ferreira, V. F.; Cunha, A. C.; Rev. Virtual Química 2012, 4.

23. Bhaduri, S.; Mukesh, D.; Homogeneous Catalysis; John Wiley \& Sons, Inc: Hoboken, NJ, 2014.

24. Dupont, J.; Quim. Nova 2000, 23, 825.

25. Reis, M. C.; Freitas, F. A.; Lachter, E. R.; Gil, R. A. S. S.; Nascimento, R. S. V.; Poubel, R. L.; Borré, L. B.; Quim. Nova 2015, 38, 1307.

26. Fukuda, H.; Kondo, A.; Noda, H.; J. Biosci. Bioeng. 2001, 92, 405.

27. Thangaraj, B.; Solomon, P. R.; Muniyandi, B.; Ranganathan, S.; Lin, L.; Clean Energy 2019, 3, 2.

28. Buffon, R.; Rev. Chemkeys 2018, 1.

29. Shriver, D. F.; Atkins, P. W.; Overton, T. L.; Rourke, J. P.; Weller, M. T.; Armstrong, F. A.; Química Inorgânica; Bookman, 2006.

30. Gama, P. E.; Gil, R. A. da S. S.; Lachter, E. R.; Quim. Nova 2010, 33, 1859.

31. Saydut, A.; Kafadar, A. B.; Aydin, F.; Erdogan, S.; Kaya, C.; Hamamci, C.; Indian J. Biotechnol. 2016, 15, 596.

32. Ramírez Sanabria, A. E.; Rodríguez Pérez, J. R.; Publicaciones e Investig. 2015, 9, 51.

33. Pilli, R. A.; Quim. Nov. na Esc. 2001, 14, 14.

34. Sheldon, R. A.; Woodley, J. M.; Chem. Rev. 2018, 118, 801.

35. Sandoval, B. A.; Hyster, T. K.; Curr. Opin. Chem. Biol. 2020, 55, 45.

36. Chen, K.; Arnold, F. H.; Nat. Catal. 2020, 3, 203.
37. Santos, S.; Puna, J.; Gomes, J.; Energies 2020, 13, 2.

38. Dalla-Vecchia, R.; Nascimento, M. D. G.; Soldi, V.; Quim. Nova 2004, 27, 623.

39. Keleti, T.; Ovádi, J.; Batke, J.; J. Mol. Catal. 1975, 1, 173.

40. Wolfenden, R.; Snider, M. J.; Acc. Chem. Res. 2001, 34, 938.

41. Liang, J.; Lalonde, J.; Borup, B.; Mitchell, V.; Mundorff, E.; Trinh, N.; Kochrekar, D. A.; Nair Cherat, R.; Pai, G. G.; Org. Process Res. Dev. 2010, 14, 193.

42. Alonso, F. O. M.; Antunes, O. A. C.; Oestreicher, E. G.; J. Braz. Chem. Soc. 2007, 18, 566.

43. Schaefer, C. A.; Silva, V. D.; Stambuk, B. U.; Nascimento, M. da G.; J. Braz. Chem. Soc. 2013, 24, 1116.

44. Liang, J.; Lalonde, J.; Borup, B.; Mitchell, V.; Mundorff, E.; Trinh, N.; Kochrekar, D. A.; Org. Process Res. Dev. 2010, 193.

45. Schmal, M.; Heterogeneous Catalysis and its Industrial Applications; 1st ed.; Springer International Publishing: Cham, 2016.

46. Yilmaz, B.; Müller, U.; Top. Catal. 2009, 52, 888.

47. Abdullah, S. H. Y. S.; Hanapi, N. H. M.; Azid, A.; Umar, R.; Juahir, H.; Khatoon, H.; Endut, A.; Renew. Sustain. Energy Rev. 2017, 70, 1040.

48. Hagen, J.; Industrial Catalysis; Wiley, 2005.

49. Gawande, M. B.; Fornasiero, P.; Zbo囚il, R.; ACS Catal. 2020, 10, 2231.

50. Fu, J.; Lym, J.; Zheng, W.; Alexopoulos, K.; Mironenko, A. V.; Li, N.; Boscoboinik, J. A.; Su, D.; Weber, R. T.; Vlachos, D. G.; Nat. Catal. 2020.

51. Yilmaz, B.; Müller, U.; Top. Catal. 2009, 52, 888.

52. Shinde, P. S.; Suryawanshi, P. S.; Patil, K. K.; Belekar, V. M.; Sankpal, S. A.; Delekar, S. D.; Jadhav, S. A.; J. Compos. Sci. 2021, 5, 75.

53. Moreno, E. L.; Rajagopal, K.; Quim. Nova 2009, 32, 538.

54. Zhu, M. M.; Du, X. L.; Zhao, Y.; Mei, B. B.; Zhang, Q.; Sun, F. F.; Jiang, Z.; Liu, Y. M.; He, H. Y.; Cao, Y.; ACS Catal. 2019, 9, 6212.

55. Védrine, J. C.; Chinese J. Catal. 2019, 40, 1627.

56. Védrine, J. C.; ChemSusChem 2019, 12, 577.

57. Chianelli, R. R.; Berhault, G.; Torres, B.; Catal. Today 2009, 147, 275.

58. Wang, G.; Li, C.; Shan, H.; ACS Catal. 2014, 4, 1139.

59. Tao, H.; Liu, S.; Luo, J.-L.; Choi, P.; Liu, Q.; Xu, Z.; J. Mater. Chem. A 2018, 6, 9650.

60. Zaera, F.; J. Phys. Chem. B 2002, 106, 4043.

61. Chen, F.; Jiang, X.; Zhang, L.; Lang, R.; Qiao, B.; Chinese J. Catal. 2018, 39, 893 .

62. Zhang, H.; Liu, G.; Shi, L.; Ye, J.; Adv. Energy Mater. 2018, 8, 1701343.

63. Cui, X.; Li, W.; Ryabchuk, P.; Junge, K.; Beller, M.; Nat. Catal. 2018, 1,385 .

64. Cheng, N.; Zhang, L.; Doyle-Davis, K.; Sun, X.; Electrochem. Energy Rev. 2019, 2, 539.

65. Su, X.; Yang, X.-F.; Huang, Y.; Liu, B.; Zhang, T.; Acc. Chem. Res. 2019, $52,656$.

66. Wang, M.; Feng, B.; Li, H.; Li, H.; Chem 2019, 5, 805.

67. Jeong, H.; Shin, S.; Lee, H.; ACS Nano 2020, 14, 14355.

68. Qiao, B.; Wang, A.; Yang, X.; Allard, L. F.; Jiang, Z.; Cui, Y.; Liu, J.; Li, J.; Zhang, T.; Nat. Chem. 2011, 3, 634.

69. Hikazudani, S.; Mochida, T.; Yano, K.; Nagaoka, K.; Ishihara, T.; Takita, Y.; Catal. Commun. 2011, 12, 1396.

70. Li, J.; Liang, X.; King, D. M.; Jiang, Y.-B.; Weimer, A. W.; Appl. Catal. B Environ. 2010, 97, 220.

71. Gole, J. L.; White, M. G.; J. Catal. 2001, 204, 249.

72. Keränen, J.; Guimon, C.; Iiskola, E.; Auroux, A.; Niinistö, L.; Catal. Today 2003, 78, 149.

73. Asakura, K.; Nagahiro, H.; Ichikuni, N.; Iwasawa, Y.; Appl. Catal. A Gen. 1999, 188, 313.

74. Wang, X.; Li, N.; Pfefferle, L. D.; Haller, G. L.; Catal. Today 2009, 146, 160.

75. Deng, W.; Frenkel, A. I.; Si, R.; Flytzani-Stephanopoulos, M.; J. Phys. Chem. C 2008, 112, 12834. 
76. Zhang, L.; Ren, Y.; Liu, W.; Wang, A.; Zhang, T.; Natl. Sci. Rev. 2018, $5,653$.

77. Su, X.; Yang, X.-F.; Huang, Y.; Liu, B.; Zhang, T.; Acc. Chem. Res. 2019, 52,656 .

78. Chen, Z.; Zhang, Q.; Chen, W.; Dong, J.; Yao, H.; Zhang, X.; Tong, X.; Wang, D.; Peng, Q.; Chen, C.; He, W.; Li, Y.; Adv. Mater. 2018, 30, 1704720.

79. Tao, H.; Choi, C.; Ding, L.-X.; Jiang, Z.; Han, Z.; Jia, M.; Fan, Q.; Gao, Y.; Wang, H.; Robertson, A. W.; Hong, S.; Jung, Y.; Liu, S.; Sun, Z.; Chem 2019, 5, 204.

80. Ftouni, J.; Muñoz-Murillo, A.; Goryachev, A.; Hofmann, J. P.; Hensen, E. J. M.; Lu, L.; Kiely, C. J.; Bruijnincx, P. C. A.; Weckhuysen, B. M.; ACS Catal. 2016, 6, 5462

81. Chen, Z.; Zhang, Q.; Chen, W.; Dong, J.; Yao, H.; Zhang, X.; Tong, X.; Wang, D.; Peng, Q.; Chen, C.; He, W.; Li, Y.; Adv. Mater. 2018, 30, 1704720.

82. Chen, J.; Ge, Y.; Guo, Y.; Chen, J.; J. Energy Chem. 2018, 27, 283.

83. Tian, S.; Gong, W.; Chen, W.; Lin, N.; Zhu, Y.; Feng, Q.; Xu, Q.; Fu, Q.; Chen, C.; Luo, J.; Yan, W.; Zhao, H.; Wang, D.; Li, Y.; ACS Catal. 2019, 5223.

84. Yan, H.; Su, C.; He, J.; Chen, W.; J. Mater. Chem. A 2018, 6, 8793.

85. Lang, R.; Li, T.; Matsumura, D.; Miao, S.; Ren, Y.; Cui, Y.-T.; Tan, Y.; Qiao, B.; Li, L.; Wang, A.; Wang, X.; Zhang, T.; Angew. Chemie Int. Ed. 2016, $55,16054$.

86. Qiao, B.; Liang, J.-X.; Wang, A.; Xu, C.-Q.; Li, J.; Zhang, T.; Liu, J. J.; Nano Res. 2015, 8, 2913.

87. Han, B.; Li, T.; Zhang, J.; Zeng, C.; Matsumoto, H.; Su, Y.; Qiao, B.; Zhang, T.; Chem. Commun. 2020, 56, 4870.

88. Yan, H.; Zhao, X.; Guo, N.; Lyu, Z.; Du, Y.; Xi, S.; Guo, R.; Chen, C.; Chen, Z.; Liu, W.; Yao, C.; Li, J.; Pennycook, S. J.; Chen, W.; Su, C.; Zhang, C.; Lu, J.; Nat. Commun. 2018, 9, 3197.

89. Yang, F.; Ding, S.; Song, H.; Yan, N.; Sci. China Mater. 2020, 63, 982.

90. Chen, F.; Li, T.; Pan, X.; Guo, Y.; Han, B.; Liu, F.; Qiao, B.; Wang, A.; Zhang, T.; Sci. China Mater. 2020, 63, 959.

91. Zhang, M.; Wang, Y.-G.; Chen, W.; Dong, J.; Zheng, L.; Luo, J.; Wan, J.; Tian, S.; Cheong, W.-C.; Wang, D.; Li, Y.; J. Am. Chem. Soc. 2017, 139, 10976.

92. Vorobyeva, E.; Chen, Z.; Mitchell, S.; Leary, R. K.; Midgley, P.; Thomas, J. M.; Hauert, R.; Fako, E.; López, N.; Pérez-Ramírez, J.; J. Mater. Chem. A 2017, 5, 16393.

93. Ruppert, A. M.; Jędrzejczyk, M.; Potrzebowska, N.; Kaźmierczak, K.; Brzezińska, M.; Sneka-Płatek, O.; Sautet, P.; Keller, N.; Michel, C.; Grams, J.; Catal. Sci. Technol. 2018, 8, 4318.

94. Liu, G.; Robertson, A. W.; Li, M. M. J.; Kuo, W. C. H.; Darby, M. T.; Muhieddine, M. H.; Lin, Y. C.; Suenaga, K.; Stamatakis, M.; Warner, J. H.; Tsang, S. C. E.; Nat. Chem. 2017, 9, 810.

95. Li, T.; Liu, F.; Tang, Y.; Li, L.; Miao, S.; Su, Y.; Zhang, J.; Huang, J.; Sun, H.; Haruta, M.; Wang, A.; Qiao, B.; Li, J.; Zhang, T.; Angew. Chemie Int. Ed. 2018, 57, 7795 .

96. Li, L.; Chang, X.; Lin, X.; Zhao, Z. J.; Gong, J.; Chem. Soc. Rev. 2020, 49, 8156.

97. Chen, Z.; Mitchell, S.; Vorobyeva, E.; Leary, R. K.; Hauert, R.; Furnival, T.; Ramasse, Q. M.; Thomas, J. M.; Midgley, P. A.; Dontsova, D.; Antonietti, M.; Pogodin, S.; López, N.; Pérez-Ramírez, J.; Adv. Funct. Mater. 2017, 27, 1605785.

98. Zhou, J.; An, W.; Wang, Z.; Jia, X.; Catal. Sci. Technol. 2019, 9, 4314.

99. Liu, L.; Corma, A.; Chem. Rev. 2018, 118, 4981.

100. Qi, K.; Chhowalla, M.; Voiry, D.; Mater. Today 2020, 40, 173.

101. Liang, S.; Hao, C.; Shi, Y.; ChemCatChem 2015, 7, 2559.

102. Li, Z.; Wang, D.; Wu, Y.; Li, Y.; Natl. Sci. Rev. 2018, 5, 673.

103. Li, J.; Stephanopoulos, M. F.; Xia, Y.; Chem. Rev. 2020, 120, 11699.

104. Kaiser, S. K.; Chen, Z.; Faust Akl, D.; Mitchell, S.; Pérez-Ramírez, J.; Chem. Rev. 2020, 120, 11703.
105. Zhang, Q.; Guan, J.; Sol. RRL 2020, 4, 2000283.

106. Chen, Y.; Ji, S.; Chen, C.; Peng, Q.; Wang, D.; Li, Y.; Joule 2018, 2, 1242.

107. Li, X.; Liu, L.; Ren, X.; Gao, J.; Huang, Y.; Liu, B.; Sci. Adv. 2020, 6, 1.

108. Liu, W.; Zhang, H.; Li, C.; Wang, X.; Liu, J.; Zhang, X.; J. Energy Chem. 2020, 47, 333

109. Liu, J.; Bunes, B. R.; Zang, L.; Wang, C.; Environ. Chem. Lett. 2018, $16,477$.

110. Sun, M.; Wu, T.; Huang, B.; Eng. Reports 2020, $2,1$.

111. Su, J.; Ge, R.; Dong, Y.; Hao, F.; Chen, L.; J. Mater. Chem. A 2018, 6, 14025.

112. Pu, Z.; Amiinu, I. S.; Cheng, R.; Wang, P.; Zhang, C.; Mu, S.; Zhao, W.; Su, F.; Zhang, G.; Liao, S.; Sun, S.; Nano-Micro Lett. 2020, 12, 21.

113. Han, B.; Lang, R.; Qiao, B.; Wang, A.; Zhang, T.; Chinese J. Catal. 2017, 38, 1498.

114. Mohanty, B.; Jena, B. K.; Basu, S.; ACS Omega 2020, 5, 1287.

115. Zhang, B. W.; Wang, Y. X.; Chou, S. L.; Liu, H. K.; Dou, S. X.; Small Methods 2019, 3, 1 .

116. Yan, H.; Su, C.; He, J.; Chen, W.; J. Mater. Chem. A 2018, 6, 8793.

117. Zhu, Y.; Wang, J.; Chu, H.; Chu, Y. C.; Chen, H. M.; ACS Energy Lett. 2020, 5,1281

118. Dou, J.; Sun, Z.; Opalade, A. A.; Wang, N.; Fu, W.; Tao, F.; Chem. Soc. Rev. 2017, 46, 2001

119. Zhao, T.; Wang, Y.; Karuturi, S.; Catchpole, K.; Zhang, Q.; Zhao, C.; Carbon Energy 2020, 2, 582.

120. Lien, H. T.; Chang, S. T.; Chen, P. T.; Wong, D. P.; Chang, Y. C.; Lu, Y. R.; Dong, C. L.; Wang, C. H.; Chen, K. H.; Chen, L. C.; Nat. Commun. 2020, 11,1 .

121. Hülsey, M. J.; Zhang, B.; Ma, Z.; Asakura, H.; Do, D. A.; Chen, W.; Tanaka, T.; Zhang, P.; Wu, Z.; Yan, N.; Nat. Commun. 2019, 10.

122. Handoko, A. D.; Wei, F.; Jenndy; Yeo, B. S.; Seh, Z. W.; Nat. Catal. 2018, $1,922$.

123. Yin, P.; Yao, T.; Wu, Y.; Zheng, L.; Lin, Y.; Liu, W.; Ju, H.; Zhu, J.; Hong, X.; Deng, Z.; Zhou, G.; Wei, S.; Li, Y.; Angew. Chemie - Int. Ed. 2016, $55,10800$.

124. Ho, V. T. T.; Pan, C. J.; Rick, J.; Su, W. N.; Hwang, B. J.; J. Am. Chem. Soc. 2011, 133, 11716.

125. Timoshenko, J.; Roldan Cuenya, B.; Chem. Rev. 2021, 121, 882.

126. DeRita, L.; Dai, S.; Lopez-Zepeda, K.; Pham, N.; Graham, G. W.; Pan, X.; Christopher, P.; J. Am. Chem. Soc. 2017, 139, 14150.

127. Li, X.; Yang, X.; Zhang, J.; Huang, Y.; Liu, B.; ACS Catal. 2019, 9, 2521.

128. Liang, S.; Hao, C.; Shi, Y.; ChemCatChem 2015, 7, 2559.

129. Wang, L.; Zhang, S.; Zhu, Y.; Patlolla, A.; Shan, J.; Yoshida, H.; Takeda, S.; Frenkel, A. I.; Tao, F.; ACS Catal. 2013, 3, 1011.

130. Li, X.; Wang, H.-Y.; Yang, H.; Cai, W.; Liu, S.; Liu, B.; Small Methods 2018, 2, 1700395 .

131. Mao, J.; Yin, J.; Pei, J.; Wang, D.; Li, Y.; Nano Today 2020, 34, 100917.

132. Liu, J.; Cao, D.; Xu, H.; Cheng, D.; Nano Sel. 2021, $2,251$.

133. Dong, C.; Li, Y.; Cheng, D.; Zhang, M.; Liu, J.; Wang, Y.-G.; Xiao, D.; Ma, D.; ACS Catal. 2020, 10, 11011.

134. Rong, H.; Ji, S.; Zhang, J.; Wang, D.; Li, Y.; Nat. Commun. 2020, 11, 5884.

135. Ji, S.; Chen, Y.; Fu, Q.; Chen, Y.; Dong, J.; Chen, W.; Li, Z.; Wang, Y.; Gu, L.; He, W.; Chen, C.; Peng, Q.; Huang, Y.; Duan, X.; Wang, D.; Draxl, C.; Li, Y.; J. Am. Chem. Soc. 2017, 139, 9795.

136. Bonanni, S.; Aït-Mansour, K.; Harbich, W.; Brune, H.; J. Am. Chem. Soc. 2012, 134, 3445.

137. Baxter, E. T.; Ha, M.-A.; Cass, A. C.; Alexandrova, A. N.; Anderson, S. L.; ACS Catal. 2017, 7, 3322.

138. Lu, J.; Serna, P.; Aydin, C.; Browning, N. D.; Gates, B. C.; J. Am. Chem. Soc. 2011, 133, 16186. 
139. Lei, Y.; Mehmood, F.; Lee, S.; Greeley, J.; Lee, B.; Seifert, S.; Winans, R. E.; Elam, J. W.; Meyer, R. J.; Redfern, P. C.; Teschner, D.; Schlog1, R.; Pellin, M. J.; Curtiss, L. A.; Vajda, S.; Science (80-. ). 2010, 328, 224.

140. Vorobyeva, E.; Fako, E.; Chen, Z.; Collins, S. M.; Johnstone, D.; Midgley, P. A.; Hauert, R.; Safonova, O. V.; Vilé, G.; López, N.; Mitchell, S.; Pérez-Ramírez, J.; Angew. Chemie Int. Ed. 2019, 58, 8724.

141. Jiao, J.; Lin, R.; Liu, S.; Cheong, W.-C.; Zhang, C.; Chen, Z.; Pan, Y.; Tang, J.; Wu, K.; Hung, S.-F.; Chen, H. M.; Zheng, L.; Lu, Q.; Yang, X.; Xu, B.; Xiao, H.; Li, J.; Wang, D.; Peng, Q.; Chen, C.; Li, Y.; Nat. Chem. 2019, 11, 222.

142. Ye, W.; Chen, S.; Lin, Y.; Yang, L.; Chen, S.; Zheng, X.; Qi, Z.; Wang, C.; Long, R.; Chen, M.; Zhu, J.; Gao, P.; Song, L.; Jiang, J.; Xiong, Y.; Chem 2019, 5, 2865.

143. Liu, J.-C.; Ma, X.-L.; Li, Y.; Wang, Y.-G.; Xiao, H.; Li, J.; Nat. Commun. 2018, 9,1610

144. Kyriakou, G.; Boucher, M. B.; Jewell, A. D.; Lewis, E. A.; Lawton, T. J.; Baber, A. E.; Tierney, H. L.; Flytzani-Stephanopoulos, M.; Sykes, E. C. H.; Science (80-. ). 2012, 335, 1209.

145. Hannagan, R. T.; Giannakakis, G.; Flytzani-Stephanopoulos, M.; Sykes, E. C. H.; Chem. Rev. 2020, 120, 12044.

146. Zhang, T.; Walsh, A. G.; Yu, J.; Zhang, P.; Chem. Soc. Rev. 2021, 50, 569.

147. Chao, T.; Luo, X.; Chen, W.; Jiang, B.; Ge, J.; Lin, Y.; Wu, G.; Wang, X.; Hu, Y.; Zhuang, Z.; Wu, Y.; Hong, X.; Li, Y.; Angew. Chemie Int. Ed. 2017, 56, 16047.

148. Mao, J.; He, C.-T.; Pei, J.; Chen, W.; He, D.; He, Y.; Zhuang, Z.; Chen, C.; Peng, Q.; Wang, D.; Li, Y.; Nat. Commun. 2018, 9, 4958.
149. Yao, Y.; Hu, S.; Chen, W.; Huang, Z.-Q.; Wei, W.; Yao, T.; Liu, R.; Zang, K.; Wang, X.; Wu, G.; Yuan, W.; Yuan, T.; Zhu, B.; Liu, W.; Li, Z.; He, D.; Xue, Z.; Wang, Y.; Zheng, X.; Dong, J.; Chang, C.-R.; Chen, Y.; Hong, X.; Luo, J.; Wei, S.; Li, W.-X.; Strasser, P.; Wu, Y.; Li, Y.; Nat. Catal. 2019, 2, 304.

150. Jirkovský, J. S.; Panas, I.; Ahlberg, E.; Halasa, M.; Romani, S.; Schiffrin, D. J.; J. Am. Chem. Soc. 2011, 133, 19432.

151. Duchesne, P. N.; Li, Z. Y.; Deming, C. P.; Fung, V.; Zhao, X.; Yuan, J.; Regier, T.; Aldalbahi, A.; Almarhoon, Z.; Chen, S.; Jiang, D.; Zheng, N.; Zhang, P.; Nat. Mater. 2018, 17, 1033.

152. Lucci, F. R.; Liu, J.; Marcinkowski, M. D.; Yang, M.; Allard, L. F.; Flytzani-Stephanopoulos, M.; Sykes, E. C. H.; Nat. Commun. 2015, 6 , 8550 .

153. Pei, G. X.; Liu, X. Y.; Wang, A.; Lee, A. F.; Isaacs, M. A.; Li, L.; Pan, X.; Yang, X.; Wang, X.; Tai, Z.; Wilson, K.; Zhang, T.; ACS Catal. 2015, $5,3717$.

154. Wang, L.; Zhang, S.; Zhu, Y.; Patlolla, A.; Shan, J.; Yoshida, H.; Takeda, S.; Frenkel, A. I.; Tao, F. (Feng); ACS Catal. 2013, 3, 1011.

155. Shan, J.; Liu, J.; Li, M.; Lustig, S.; Lee, S.; Flytzani-Stephanopoulos, M.; Appl. Catal. B Environ. 2018, 226, 534.

156. Marcinkowski, M. D.; Liu, J.; Murphy, C. J.; Liriano, M. L.; Wasio, N. A.; Lucci, F. R.; Flytzani-Stephanopoulos, M.; Sykes, E. C. H.; ACS Catal. 2017, 7, 413.

157. Wan, J.; Chen, W.; Jia, C.; Zheng, L.; Dong, J.; Zheng, X.; Wang, Y.; Yan, W.; Chen, C.; Peng, Q.; Wang, D.; Li, Y.; Adv. Mater. 2018, 30, 1705369 . 